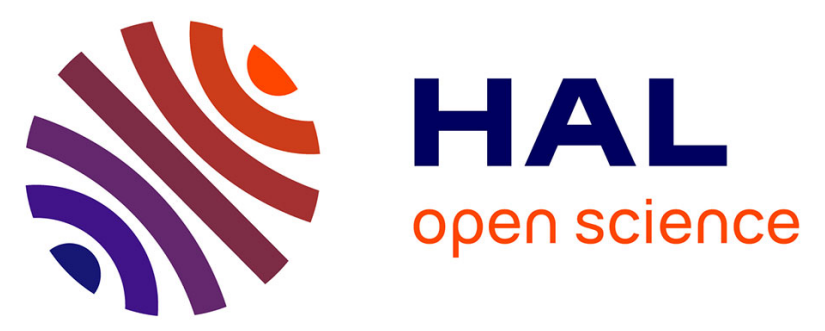

\title{
In Silico Design of Nitrocoumarins as Near-UV Photoinitiators: Toward Interesting Opportunities in Composites and 3D Printing Technologies
}

Hijazi Akram, Frederic Dumur, Mira Abdallah, Akram Hijazi, Bernadette Graff, Jean-Pierre Fouassier, Frédéric Dumur, Jacques Lalevee

\section{To cite this version:}

Hijazi Akram, Frederic Dumur, Mira Abdallah, Akram Hijazi, Bernadette Graff, et al.. In Silico Design of Nitrocoumarins as Near-UV Photoinitiators: Toward Interesting Opportunities in Composites and 3D Printing Technologies. ACS Applied Polymer Materials, 2020, 2 (7), pp.2890-2901. 10.1021/acsapm.0c00409 . hal-02895888

\section{HAL Id: hal-02895888 \\ https://hal.science/hal-02895888}

Submitted on 20 Jul 2020

HAL is a multi-disciplinary open access archive for the deposit and dissemination of scientific research documents, whether they are published or not. The documents may come from teaching and research institutions in France or abroad, or from public or private research centers.
L'archive ouverte pluridisciplinaire HAL, est destinée au dépôt et à la diffusion de documents scientifiques de niveau recherche, publiés ou non, émanant des établissements d'enseignement et de recherche français ou étrangers, des laboratoires publics ou privés. 


\title{
In Silico Design of Nitrocoumarins as Near-UV Photoinitiators: Toward Interesting Opportunities in Composites and 3D Printing Technologies \\ Mira Abdallah ${ }^{1,2,3}$, Akram Hijazi ${ }^{3}$, Bernadette Graff ${ }^{1,2}$, Jean-Pierre Fouassier ${ }^{1,2}$, Frédéric Dumur* $^{*}$, Jacques Lalevée*1,2 \\ ${ }^{1}$ Université de Haute-Alsace, CNRS, IS2M UMR 7361, F-68100 Mulhouse, France \\ ${ }^{2}$ Université de Strasbourg, France \\ ${ }^{3}$ EDST, Université Libanaise, Campus Hariri, Hadath, Beyrouth, Liban. \\ ${ }^{4}$ Aix Marseille Univ, CNRS, ICR UMR 7273, F-13397 Marseille, France
}

Corresponding author: jacques.lalevee@uha.fr; frederic.dumur@univ-amu.fr

\begin{abstract}
In this work, the in-silico rational design of new photoinitiators by molecular modeling for specific wavelength (here $405 \mathrm{~nm}$ ) and specific applications (3D printing, composites) is reported. A large number of (keto)coumarin derivatives were investigated by molecular modeling and their synthesis and more detailed photochemical investigations are based on obtaining structures having both excellent predicted light absorption properties @ $405 \mathrm{~nm}$ and high excited state energy levels (to ensure high photochemical reactivity). More particularly, four new families of coumarins were designed (4 of the 19 proposed coumarins were never synthesized (N2,M6,T1,T6)): the first family is based on Nitrocoumarins (N1-N6), the second one on Methoxybenzene-based coumarins and Ethoxycoumarins (M1-M6), the third one on Thiophene-based coumarins (T1-T6) and the last family studied concerns Alkyne-based coumarin (A1). The purpose of this work concerns the study of the photoinitiating ability of these compounds in different monomers for different polymerization processes (free radical, cationic) using FTIR technique. The different compounds reported in this work are very efficient to initiate the free radical polymerization of (meth)acrylates but also the cationic polymerization of epoxides upon mild irradiation conditions using a Light
\end{abstract}


Emitting Diode (LED) at $405 \mathrm{~nm}$ as visible light source. Nitrocoumarins were identified as the best candidates for photoinitiation among the different families of coumarins investigated in this work. More precisely, nitrocoumarins are characterized by very good polymerization profiles, great final reactive function conversions (FC) and also high rates of polymerization (Rp). The electrochemical and photochemical properties of the different compounds were also studied to get a deeper insight into the photochemical mechanisms supporting the initiation process. A full picture of the involved photochemical mechanisms is provided. Thanks to the astounding polymerization initiating ability of these coumarins, their use in 3D printing applications can be worthwhile. Remarkably, using these compounds, the preparation of photocomposites was possible even in difficult light penetration conditions resulting from the presence of fibers inside the resins.

KEYWORDS: Coumarin; Light-emitting diode; Photocomposite; 3D printing.

\section{INTRODUCTION}

Coumarins are usually classified in the family of fluorescent organic heterocyclic compounds. Coumarins can be obtained synthetically but also, they can be found in the nature as exemplified with Esculetin, Ammoresinol, Osthole, Coumermycin, Chartreusin, Imperatorin, Psoralen, Bergapten, Anthogenol, Felamidin, Grandivittin, Xanthyletin, and so on. The coumarin scaffold is of high interest in many fields such as polymer science, medicine, biology... Moreover, coumarins are commonly found in the production of perfumes and cosmetics [1-7], cigarettes [26] and alcoholic beverages [8]. Based on the literature, coumarins have also been used in homo and copolymerization in order to prepare polymers based on methacrylate bearing coumarin side group by mean of a free radical polymerization carried out at $60^{\circ} \mathrm{C}$. These latter prepared polymers 
are characterized by a dielectric behavior and a remarkable thermal stability [9]. Coumarin derivatives can also be used as starting materials for the synthesis of polyesters containing coumarin dimers, these polymers being obtained by photochemical dimerization of their dicarboxylates upon UV light irradiation [10]. Besides, the use of coumarin-containing polymers in electro-optical but also in biopolymer studies has been reported in the literature [11]. Moreover, the ability of coumarin derivatives to act as photosensitizers or photoinitiators has been deeply studied and influence of the substitution pattern was notably investigated. Parallel to coumarins, other derivatives such as keto-coumarins were also studied [12-27]. Recently, new coumarins have also been examined by us for 3D printing applications, photocomposites synthesis but also for the preparation of hydrogels (widely used in biomedical applications), highlighting the use of watersoluble photoinitiators [28]. Due to these attractive properties that characterize coumarins, a large number of coumarin derivatives were synthesized and investigated in our study.

In the present paper, the in-silico rational design of new coumarins (See Scheme 1) by molecular modeling for highly specific wavelength (here $405 \mathrm{~nm}$ ) and applications (3D printing, composites synthesis) will be presented as a powerful tool for the development of high performance photosensitive systems able to initiate the photopolymerization processes. It should be noted that the use of photopolymerization in the field of composites presents a key challenge for fast and efficient composites preparation whereas the prevention of light penetration due to the diffusion of light by the fillers remains an unanswered challenge [29]. Therefore, the development of new photoinitiators absorbing @405nm and able to be efficient even for low light intensity in difficult light penetration conditions (e.g. composites) is urgently needed. Besides, for 3D printing based on stereolithography, the $405 \mathrm{~nm}$ wavelength is now recognized as the reference wavelength ensuring a safe and cheap irradiation set-up. In this work, different coumarins were specifically 
designed by molecular modeling in order to present good light absorption properties @ 405nm and high excited state energy levels (thus ensuring a high photochemical reactivity). The most promising structures were synthesized in a second step. The new proposed coumarins are incorporated into two and three-component photoinitiating systems, in the presence of different additives or co-initiators.

Four main groups of coumarins (noted Coum) were designed: i) Nitrocoumarins, ii) Methoxybenzene-based coumarins and Ethoxycoumarins, iii) Thiophene-based coumarins and iv) Alkyne-based coumarin. The different compounds are characterized by excellent absorption properties in the near-UV and visible range ensuring a good overlap with the emission spectra of the near-UV and visible LEDs (e.g. LED @375 and @ 405 nm) used for this study. Good performance in terms of polymerization profiles, rates of polymerization $(\mathrm{Rp})$ but also final reactive function conversions (FCs) have been noticed with these derivatives especially with the first family. The structure/reactivity/efficiency relationships are discussed based on different techniques such as UV-visible spectroscopy, fluorescence spectroscopy, cyclic voltammetry, electron spin resonance (ESR) and Real-time Fourier Transform Infrared spectroscopy (RT-FTIR).

On the other hand, 3D printing technologies are now strongly required for a wide range of applications such as 3D organ printing technology used in biomedical engineering [30], 3D food printing [31], radiology [32], and many other applications. That is why the development of new photosensitive 3D printing systems is extremely desired. In fact, the huge reactivity of the investigated compounds successfully allowed their applications in 3D printing experiments.

Otherwise, thanks to the improved light weight and mechanical properties that characterize composite materials, these latter are highly desired in different industrial fields such as aerospace applications [33,34], automotive [34], sports equipment [35], and so on. Taking into account these 
attractive properties, we were interested in using the different coumarin derivatives reported in this work for the preparation of thick glass fibers/(meth)acrylate photocomposites.

First family :

Nitrocoumarins

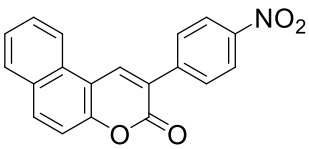

N1

Second family :

Methoxybenzene-based

coumarins and Ethoxycoumarin

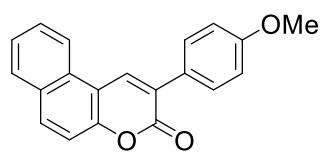

M3

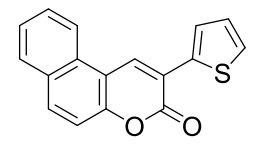

T3

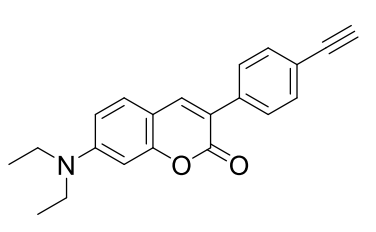

A1

Fourth family :

Alkyne-based coumarin<smiles>[2H]c1cc2cc(-c3ccc(I)cc3)c(=O)oc2c([2H])c1C</smiles>

N2-N6

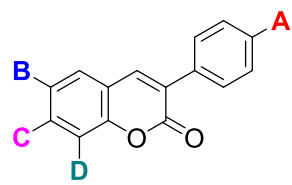

M1,M2,M4-M6

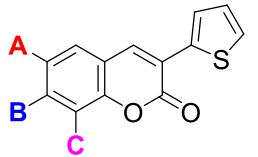

T1,T2,T4-T6
N2: $A=N_{2}, B=H, C=H, D=O E t$

N3: $A=\mathrm{NO}_{2}, \mathrm{~B}=\mathrm{H}, \mathrm{C}=\mathrm{OH}, \mathrm{D}=\mathrm{H}$

N4: $A=\mathrm{NO}_{2}, B=\mathrm{NO}_{2}, C=\mathrm{H}, \mathrm{D}=\mathrm{H}$

N5: $A=\mathrm{NO}_{2}, B=\mathrm{H}, \mathrm{C}=\mathrm{H}, \mathrm{D}=\mathrm{H}$

N6: $A=B r, B=N_{2}, C=H, D=H$

M1: $A=$ OMe, $B=H, C=H, D=O E t$

$M 2: A=O M e, B=H, C=H, D=H$

M4: $A=O M e, B=\mathrm{NO}_{2}, C=H, D=H$

M5 : $A=O M e, B=H, C=O H, D=H$

$M 6: A=B r, B=H, C=H, D=O E t$

T1: $A=H, B=H, C=O E t$

T2: $\mathrm{A}=\mathrm{CH}_{3}, \mathrm{~B}=\mathrm{H}, \mathrm{C}=\mathrm{H}$

T4: $A=H, B=H, C=H$

T5 : $A=H, B=O H, C=H$

T6: $A=\mathrm{NO}_{2}, B=\mathrm{H}, \mathrm{C}=\mathrm{H}$

Scheme 1. Chemical Structures of the Different Coumarins Examined in this Work.

\section{EXPERIMENTAL PART}

\subsection{Synthesis of Coumarins}

Coumarins derivatives are an important class of compounds finding applications in research fields such as cosmetic, perfumes, pharmaceutical and agricultural industries [36]. If different synthetic routes have been developed over the years to access to these bio-inspired molecules, the Pechmann, Perkin or Knoevenagel reactions remain the most straightforward routes [37-41]. As the main difference between the three main synthetic routes, the Pechmann and the 
Perkin reactions are carried out under acidic conditions whereas the Knoevenagel reaction is performed in basic conditions. In the present case, all coumarins were prepared following a modified version of the Perkin reaction, namely the Perkin-Oglialoro condensation [42]. Thus, N1-N6, M1-M6 and T1-T6 were obtained by refluxing the appropriate phenylacetic acid or thiophenephenylacetic acid derivative with a salicylaldehyde derivative in acetic anhydride, in the presence of sodium acetate, as shown in the Scheme 2. 
<smiles>O=Cc1c(O)ccc2ccccc12</smiles><smiles>[R]c1ccc(CC(=O)O)cc1</smiles>

Acetic anhydride

sodium acetate reflux overnight

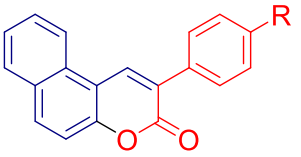

$\mathrm{N} 1: \mathrm{R}=\mathrm{NO}_{2}, 85 \%$ yield M3 : $R=$ OMe, $76 \%$ yield<smiles>[2H]c1c([B])cc(C=O)c(O)c1C</smiles><smiles>Cc1ccc(CC(=O)O)cc1</smiles>

Acetic anhydride sodium acetate reflux overnight

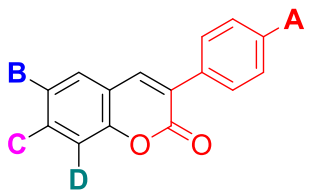

N2 : $A=\mathrm{NO}_{2}, \mathrm{~B}=\mathrm{H}, \mathrm{C}=\mathrm{H}, \mathrm{D}=\mathrm{OEt}, 89 \%$ yield N3: $A=\mathrm{NO}_{2}, \mathrm{~B}=\mathrm{H}, \mathrm{C}=\mathrm{OH}, \mathrm{D}=\mathrm{H}, 78 \%$ yield N4: $A=\mathrm{NO}_{2}, \mathrm{~B}=\mathrm{NO}_{2}, \mathrm{C}=\mathrm{H}, \mathrm{D}=\mathrm{H}, 84 \%$ yield N5: $A=\mathrm{NO}_{2}, B=\mathrm{H}, \mathrm{C}=\mathrm{H}, \mathrm{D}=\mathrm{H}, 88 \%$ yield N6: $A=B r, B=N_{2}, C=H, D=H, 78 \%$ yield M1 : $A=O M e, B=H, C=H, D=O E t, 72 \%$ yield M2 : $A=O M e, B=H, C=H, D=H, 85 \%$ yield M4 : $A=\mathrm{OMe}, \mathrm{B}=\mathrm{NO}_{2}, \mathrm{C}=\mathrm{H}, \mathrm{D}=\mathrm{H}, 85 \%$ yield M5 : $\mathrm{A}=\mathrm{OMe}, \mathrm{B}=\mathrm{H}, \mathrm{C}=\mathrm{OH}, \mathrm{D}=\mathrm{H}, 74 \%$ yield M6 : $A=B r, B=H, C=H, D=O E t, 79 \%$ yield<smiles>O=Cc1c(O)ccc2ccccc12</smiles><smiles>O=C(O)Cc1cccs1</smiles>

$\underset{\text { scetic anhydride }}{\stackrel{\text { sodium acetate }}{\text { reflux overnight }}}$
. $74 \%$ yield

Acetic anhydride sodium acetate reflux overnight

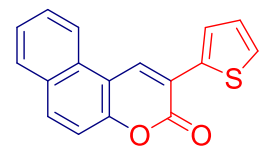

T3

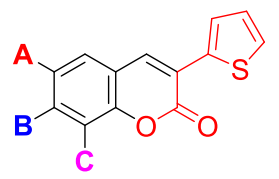

T1 : A $=\mathrm{H}, \mathrm{B}=\mathrm{H}, \mathrm{C}=\mathrm{OEt}, 73 \%$ yield T2 : $A=\mathrm{CH}_{3}, \mathrm{~B}=\mathrm{H}, \mathrm{C}=\mathrm{H}, 82 \%$ yield T4 : $A=H, B=H, C=H, 86 \%$ yield T5 : $A=\mathrm{H}, \mathrm{B}=\mathrm{OH}, \mathrm{C}=\mathrm{H}, 85 \%$ yield T6 : $A=\mathrm{NO}_{2}, \mathrm{~B}=\mathrm{H}, \mathrm{C}=\mathrm{H}, 84 \%$ yield 


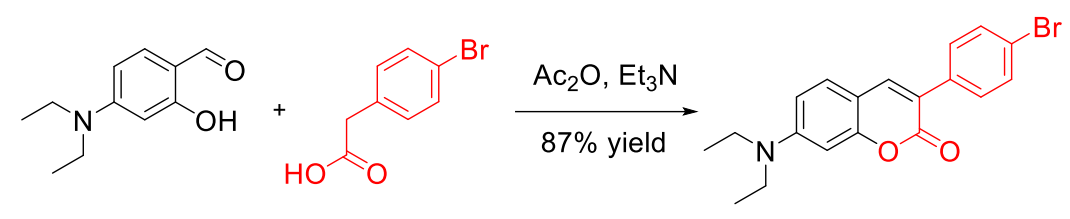

$$
\begin{aligned}
& \mathrm{Pd}\left(\mathrm{PPh}_{3}\right)_{2} \mathrm{Cl}_{2}, \mathrm{Cul}, \mathrm{PPh}_{3} \\
& \text { trimethylsilylacetylene, } \mathrm{NEt}_{3}, \mathrm{THF} \\
& 95 \% \text { yield }
\end{aligned}
$$

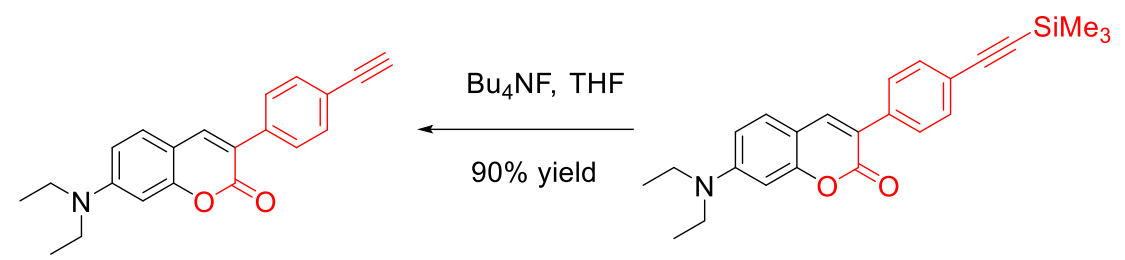

A1

Scheme 2. Synthetic Route to Coumarins N1-N6, M1-M6, T1-T6, and A1.

All dyes could be obtained as solids with reaction yields ranging from $72 \%$ for $\mathbf{M} 2$ to $89 \%$ for N2. Conversely, A1 was prepared in three steps, by first reacting 4-(diethylamino)-2hydroxybenzaldehyde with 4-bromophenylacetic acid, producing the intermediate bromocoumarin in $87 \%$ yield. In a second step, the Pd-catalyzed Sonogashira cross-coupling reaction of the halogenated coumarin with trimethylsilylacetylene followed by the removal of the trimethylsilyl group using tetrabutylammonium fluoride afforded A1. In turn, coumarin A1 could be prepared with an overall yield of $74 \%$ yield for the three steps.

\subsection{Commercial Chemical Compounds}

All commercial chemical compounds were selected with highest purity available and used as received (Scheme 3). Di-tert-butyl-diphenyl iodonium hexafluorophosphate (Iod or SpeedCure 938) was obtained from Lambson Ltd. $N$-Phenylglycine (NPG), ethyl 4-(dimethylamino)benzoate (EDB), bisphenol A-glycidyl methacrylate (BisGMA), and triethyleneglycol dimethacrylate 
(TEGDMA) were obtained from Sigma Aldrich. (3,4-Epoxycyclohexane)methyl 3,4epoxycyclohexylcarboxylate (EPOX; Uvacure 1500) and trimethylolpropane triacrylate (TMPTA) were obtained from Allnex. TMPTA (or BisGMA/TEGDMA) and EPOX were selected as benchmarked monomers for radical and cationic polymerization, respectively.

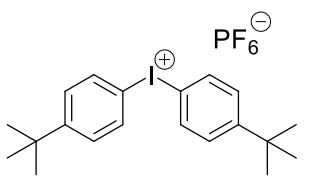

Speedcure 938 (lod)

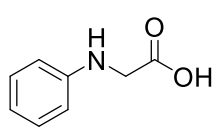

N-phenylglycine (NPG)

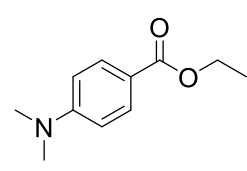

Ethyl 4-dimethylaminobenzoate (EDB)

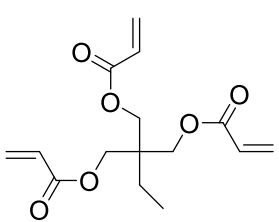

TMPTA

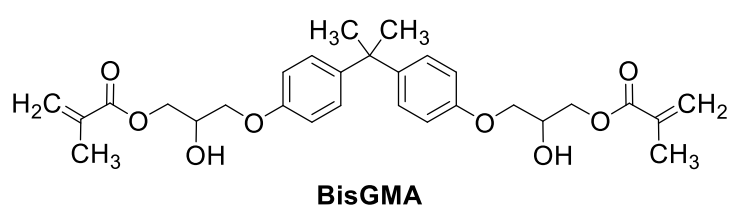

BisGMA<smiles>C=C(C)C(=O)OCCOCCOCCOC(=O)C(=C)C</smiles>

TEGDMA

Scheme 3. Chemical Structures of the Commercially Available Chemicals Used in this Study.

\subsection{Light Irradiation Sources}

The following Light-Emitting Diodes (LEDs): (i) LED @375 nm; incident light intensity on the surface of the sample: $\mathrm{I}_{0}=40 \mathrm{~mW} \cdot \mathrm{cm}^{-2}$; (ii) LED @ 405nm $\left(\mathrm{I}_{0}=110 \mathrm{~mW} \cdot \mathrm{cm}^{-2}\right)$ have been used as light irradiation sources.

\subsection{Cationic Photopolymerization (CP) and Free Radical Photopolymerization (FRP)}

In this study, Coumarin/Iodonium salt (or NPG or EDB) $(0.2 \% / 1 \% \mathrm{w} / \mathrm{w}$ ) systems have been used as two-component photoinitiating systems (PISs) for FRP and/or CP. On the other hand, the three-component photoinitiating systems (PISs) are mainly based on Coumarin/Iod/NPG 
$(0.2 \% / 1 \% / 1 \% \mathrm{w} / \mathrm{w})$ for FRP. The weight percent of the different chemicals included in the photoinitiating system are given in comparison to the monomer content. The CP of EPOX films (thickness $\sim 25 \mu \mathrm{m}$ ) was performed under air using a $\mathrm{BaF}_{2}$ pellet as substrate. For the FRP of thin TMPTA films, the experiments were carried out in laminate. The evolution of the epoxy or acrylate functions were followed by real-time FTIR spectroscopy at about $790 \mathrm{~cm}^{-1}$ and $1630 \mathrm{~cm}^{-1}$, respectively. The FRP of $1.4 \mathrm{~mm}$ (meth)acrylate thick samples were carried out under air. The procedure was presented in detail in [43-45].

\subsection{Free Energy Changes for Electron Transfer Reactions}

The redox potentials of coumarin derivatives $\left(\mathrm{E}_{\mathrm{ox}}\right.$ and $\left.\mathrm{E}_{\mathrm{red}}\right)$ were measured by cyclic voltammetry as presented by us in [45]. According to the classical free-energy change equation (eq. 1) [46], the free energy change $\left(\Delta \mathrm{G}_{\mathrm{et}}\right)$ for the different electron transfer reaction can be calculated. In eq. 1, $\mathrm{E}_{\mathrm{ox}}, \mathrm{E}_{\mathrm{red}}, \mathrm{E}_{\mathrm{S} 1}$ or $\mathrm{E}_{\mathrm{T} 1}$ and $\mathrm{C}$ stand for the oxidation potential of the electron donor, the reduction potential of the electron acceptor, the excited state energy (singlet or triplet) and the coulombic term for the initially formed ion pair, respectively. $\mathrm{C}$ can be neglected in polar solvents.

$$
\Delta \mathbf{G}_{\text {et }}=\mathbf{E}_{\mathrm{ox}}-\mathbf{E}_{\mathrm{red}}-\mathbf{E}_{(\mathbf{S 1} \text { or T1 })}^{*} \mathbf{C}
$$

\subsection{ESR Spin-Trapping (ESR-ST) Experiments}

X-Band spectrometer (Magnettech MS400) was used for ESR-ST experiments. Phenyl- $N$ tert-butylnitrone (PBN) was selected as spin-trap agent according to a procedure described by us in $[44,45]$. The PEST WINSIM program was used for ESR spectrum simulations.

\subsection{UV-visible Absorption and Photolysis Experiments}


JASCO V730 UV-visible spectrometer was used to study the light absorption properties of the different coumarins.

\subsection{Fluorescence Experiments}

JASCO FP-6200 spectrofluorimeter was used to study the fluorescence properties of the examined compounds.

\subsection{Computational Procedure}

Density functional theory DFT level was selected for the calculations as presented by us in [47].

\subsection{D Printing Experiments using Laser Diode}

3D printing experiments were carried out using a laser diode @ 405nm (spot size around 50 $\mu \mathrm{m})$. The photopolymerization of different photosensitive resins was achieved under air and the generated 3D patterns have been characterized by a numerical optical microscopy (DSX-HRSU from OLYMPUS corporation).

\subsection{UV conveyor Experiments}

In order to cure composites, Dymax-UV LED conveyor was used. The prepregs (glass fibers impregnated with the organic resin 50\%/50\% w/w) were irradiated to obtain the photocomposites. The UV conveyor (belt speed $=2 \mathrm{~m} / \mathrm{min}$ ) is equipped with a $120 \mathrm{~mm}$ wide Teflon-coated belt and a LED@395 nm (4W/cm²).

\section{RESULTS AND DISCUSSION}

\subsection{Design of Coumarins for Near-UV or Visible light}


In this in-silico design of coumarins by molecular modeling, a large number of derivatives was first studied (more than 150 structures). Coumarins characterized by both excellent predicted light absorption properties@405 nm and high excited state energy levels ensuring a high photochemical reactivity were selected. More particularly, four families of coumarins fulfilling the requirements were synthesized.

The UV-Visible absorption measurements of the coumarins were carried out in acetonitrile. The experimental spectra are depicted in Figure 1 and the molar absorption coefficients $(\varepsilon)$ of all compounds are gathered in the Table 1 . Remarkably, all the coumarins are characterized by excellent light absorption properties in the near-UV and visible range (spectral range about 270$500 \mathrm{~nm}$ ), which ensure a very good matching of their absorptions with the emission spectra of the near-UV or visible LEDs e.g. $\boldsymbol{\varepsilon}(\mathbf{N} 1)=17820 \mathrm{M}^{-1} \cdot \mathrm{cm}^{-1}$ at $\lambda_{\max }=376 \mathrm{~nm} ; \boldsymbol{\varepsilon}(\mathbf{T 3})=10280 \mathrm{M}^{-1} \cdot \mathrm{cm}^{-1}$ at $\lambda_{\max }=386 \mathrm{~nm}, \varepsilon_{(\mathbf{A} \mathbf{1})}=2560 \mathrm{M}^{-1} \cdot \mathrm{cm}^{-1}$ at $\lambda_{\max }=409 \mathrm{~nm}$ - Table 1.

The optimized geometries as well as the frontier orbitals (Highest Occupied Molecular Orbital HOMO and Lowest Unoccupied Molecular Orbital LUMO) for some representative coumarins are shown in Figure 2 and the others are presented in Figure S1. Both the HOMO and LUMO energy levels are strongly delocalized all over the $\pi$-scaffold. In fact, the high delocalization of both the HOMO and LUMO energy levels over the entire structure is in full agreement with a reduction of the HOMO-LUMO gap, leading to a bathochromic shift of the absorption. As evidenced in the Figures 2 and S1, a charge transfer character can be observed for some derivatives (HOMO and LUMO being localized at a different place). 
(A)

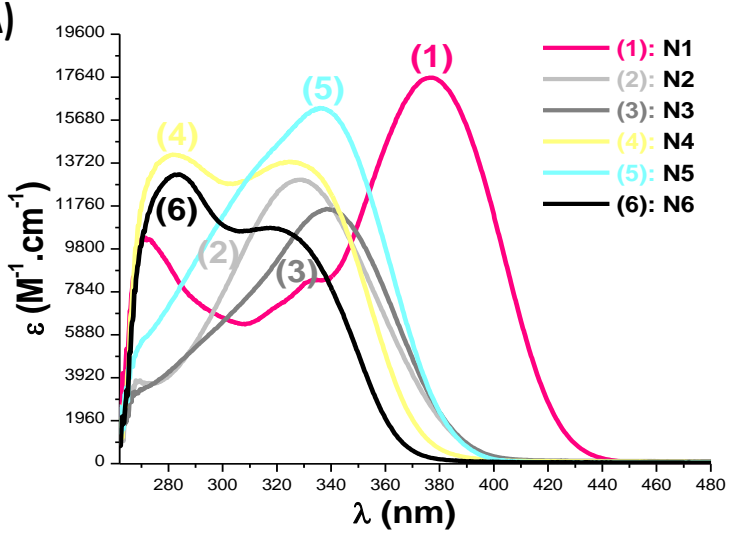

(C)

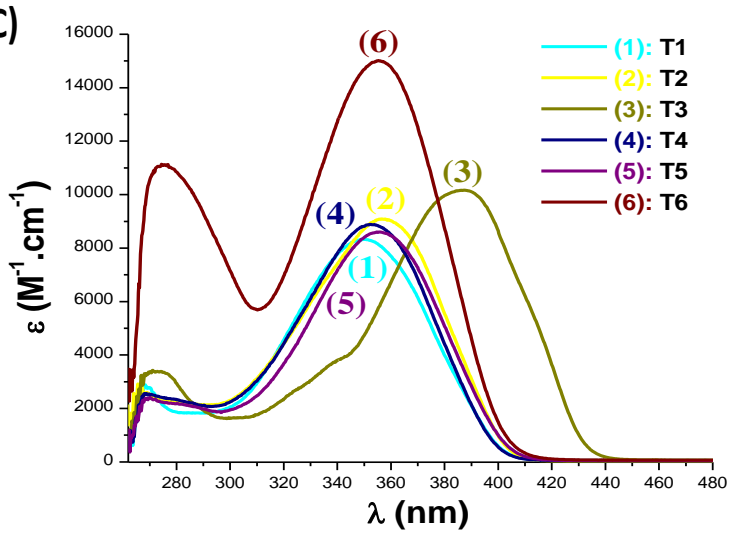

(B)

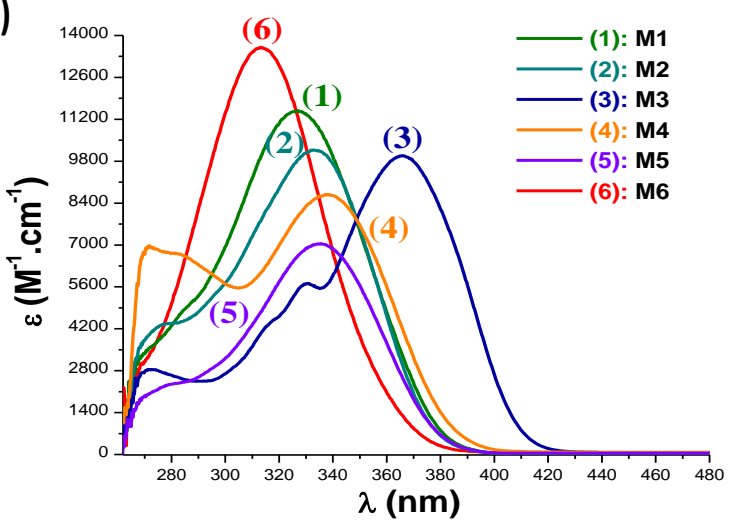

(D)

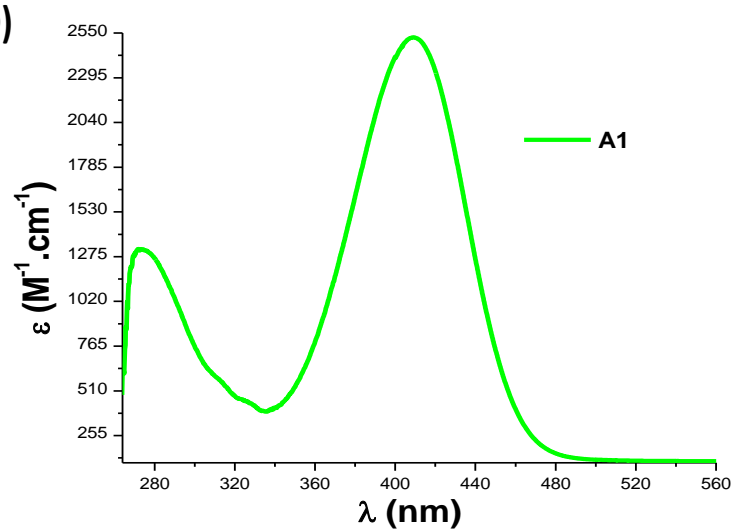

Figure 1. Absorption Spectra of the Investigated Coumarins in Acetonitrile (ACN): (A): First Family: Nitrocoumarins; (B): Second Family: Methoxybenzene-based Coumarins and Ethoxycoumarins; (C): Third Family: Thiophene-based Coumarins; and (D): Fourth Family: Alkyne-based Coumarin.

Table 1. Parameters Highlighting the Light Absorption Properties of the Coumarins: Maximum Absorption Wavelengths $\lambda_{\max }$, Molar Absorption Coefficients at $\lambda_{\max }$ and Molar Absorption Coefficients@405nm.

\begin{tabular}{|c|c|c|c|c|}
\cline { 2 - 5 } \multicolumn{1}{c|}{} & $\mathbf{P I}$ & $\lambda_{\max }(\mathbf{n m})$ & $\varepsilon_{\max }\left(\mathbf{M}^{-1} \cdot \mathbf{c m}^{-1}\right)$ & $\varepsilon_{@ 405 n m}\left(\mathbf{M}^{-1} \cdot \mathbf{c m}^{-1}\right)$ \\
\hline \multirow{4}{*}{$\begin{array}{c}\text { First Family: } \\
\text { Nitrocoumarins }\end{array}$} & $\mathbf{N 1}$ & 376 & 17820 & $\mathbf{9 7 5 0}$ \\
\cline { 2 - 5 } & $\mathbf{N 2}$ & 329 & 13110 & $\mathbf{2 3 0}$ \\
\cline { 2 - 5 } & $\mathbf{N 3}$ & 339 & 11760 & $\mathbf{3 3 0}$ \\
\cline { 2 - 5 } & $\mathbf{N 4}$ & 325 & 13940 & $\mathbf{3 2 0}$ \\
\cline { 2 - 5 } & $\mathbf{N 5}$ & 336 & 16410 & $\mathbf{3 0 0}$ \\
\cline { 2 - 5 } & $\mathbf{N 6}$ & 317 & 10950 & $\mathbf{1 4 5}$ \\
\hline
\end{tabular}




\begin{tabular}{|c|c|c|c|c|}
\hline \multirow{6}{*}{$\begin{array}{l}\text { Second Family: } \\
\text { Methoxybenzene- } \\
\text { based coumarins } \\
\text { and } \\
\text { Ethoxycoumarins }\end{array}$} & M1 & 327 & 11620 & 190 \\
\hline & M2 & 333 & 10280 & 160 \\
\hline & M3 & 366 & 10110 & 1920 \\
\hline & M4 & 338 & 8790 & 200 \\
\hline & M5 & 335 & 7130 & 135 \\
\hline & M6 & 313 & 13760 & 260 \\
\hline \multirow{6}{*}{$\begin{array}{c}\text { Third Family: } \\
\text { Thiophene-based } \\
\text { coumarins }\end{array}$} & T1 & 350 & 8430 & 330 \\
\hline & $\mathrm{T} 2$ & 357 & 9210 & 530 \\
\hline & T3 & 386 & 10280 & 7710 \\
\hline & T4 & 353 & 8995 & 345 \\
\hline & T5 & 356 & 8695 & 560 \\
\hline & T6 & 356 & 15210 & 940 \\
\hline $\begin{array}{l}\text { Fourth Family: } \\
\text { Alkyne-based } \\
\text { coumarin }\end{array}$ & A1 & 409 & 2560 & 2530 \\
\hline
\end{tabular}




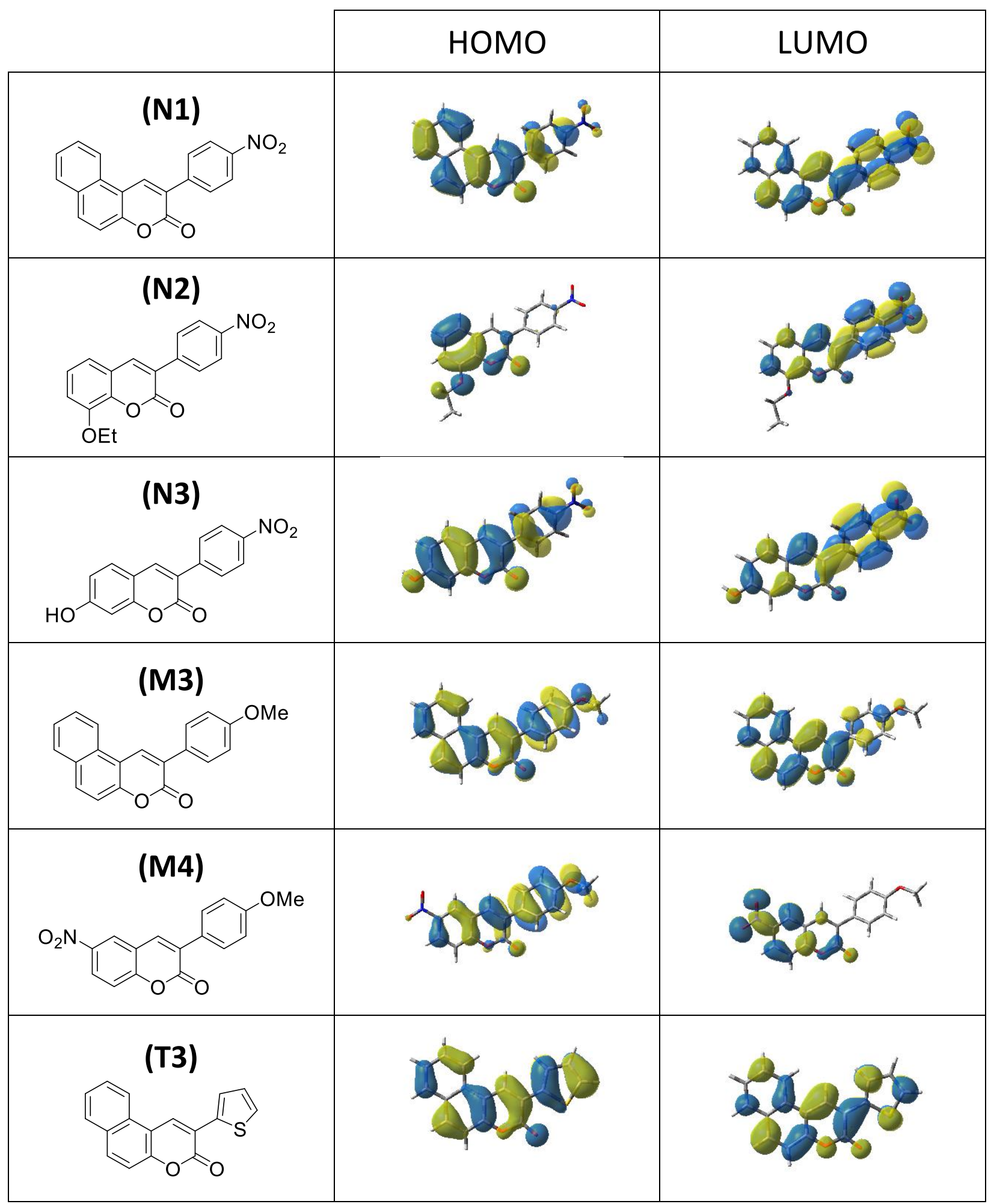




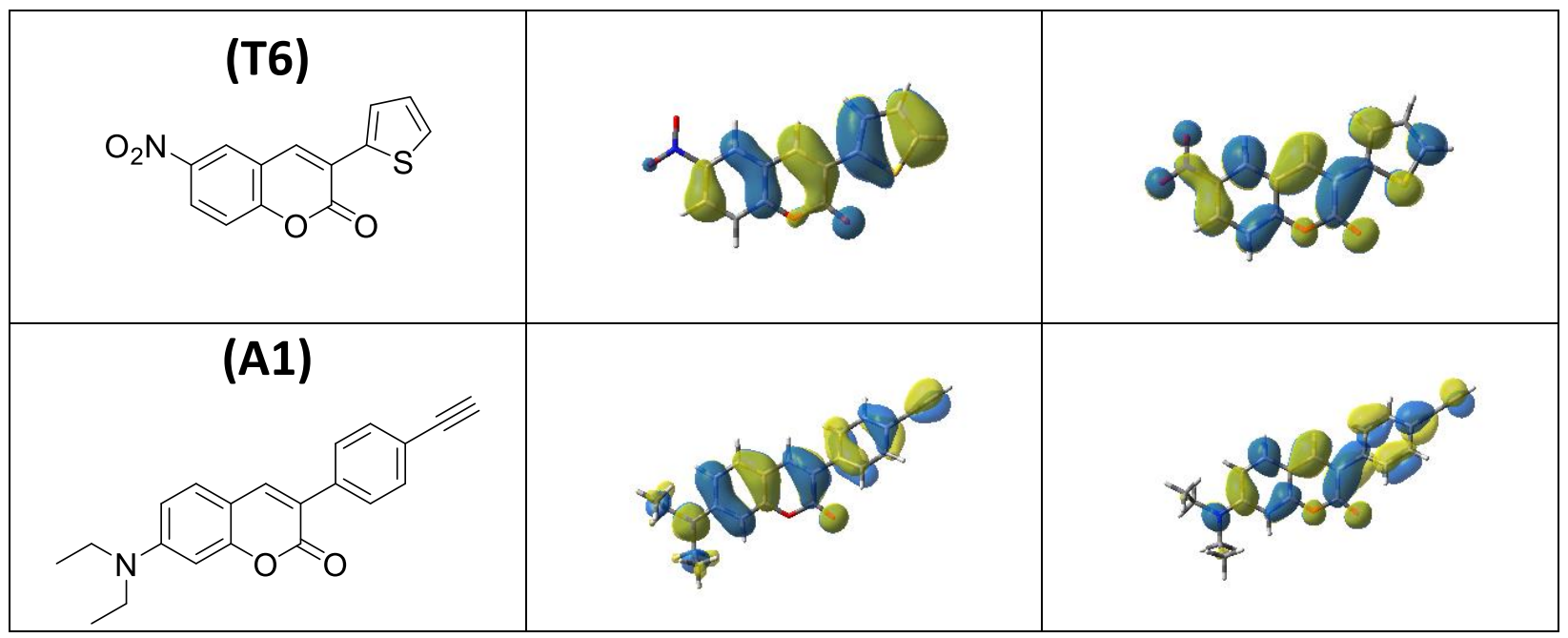

Figure 2. Contour Plots of HOMOs and LUMOs for Some Coumarins (Isovalue $=0.02$ ).

\subsection{Cationic Photopolymerization (CP) of Epoxides}

The proposed coumarins have been tested for the CP of epoxides (using EPOX as a standard monomer) in thin films $(25 \mu \mathrm{m})$ which was performed under air. The $\mathrm{CP}$ in the presence of the two-component photoinitiating system based on Coum/Iod combinations $(0.2 \% / 1 \%$ w/w) led to good polymerization efficiencies in terms of final epoxy function conversions (FCs) when irradiated with the LED @ $405 \mathrm{~nm}$ as a mild irradiation source (e.g. FC = 54\% with $0.2 \%$ T2 (w/w); Figure 3A, curve 2; Table 2). In the same irradiation conditions, Iod and coumarin alone were tested and no polymerization was observed, highlighting the crucial role of the two-component systems for the overall performance. Moreover, a new peak assigned to the formation of the polyether network in the course of the photopolymerization reaction appears at $\sim 1080 \mathrm{~cm}^{-1}$ (see Figure 3B).

The trend of efficiency for CP (i.e. for the Rp) using LED @405 nm follows the order T2 >> N1 > A1 > T5 > T3 $>$ P3 >> T4. This behavior is not directly linked to their respective absorption properties $(\boldsymbol{\varepsilon} @ \mathbf{4 0 5 n m})$ that follow another trend (i.e. N1 >> T3 >> A1 >> M3 >> T5 >> 
T2 >> T4). For example, T2 is the most efficient PI but it is not characterized by the highest molar absorption coefficient $\left(\boldsymbol{\varepsilon} @ 405 \mathrm{~nm} \sim 530 \mathrm{M}^{-1} . \mathrm{cm}^{-1}\right.$ for $\mathbf{T} 2$ compared to that of $\mathbf{N 1} \sim 9750 \mathrm{M}^{-1} . \mathrm{cm}^{-1}$; Table 1). Therefore, the ability of these coumarins are also related to their photochemical reactivity with the iodonium salt as well as the ability of the generated radical cation $\left(\mathrm{Coum}^{\bullet+}\right)$ to initiate the CP process. In addition, the initiation ability can be also connected to the formation of a Brönsted acid.

Furthermore, the other coumarins are tested for the $\mathrm{CP}$ of thin epoxides films in the presence of the iodonium salt under the same irradiation conditions, and no polymerization occurred.
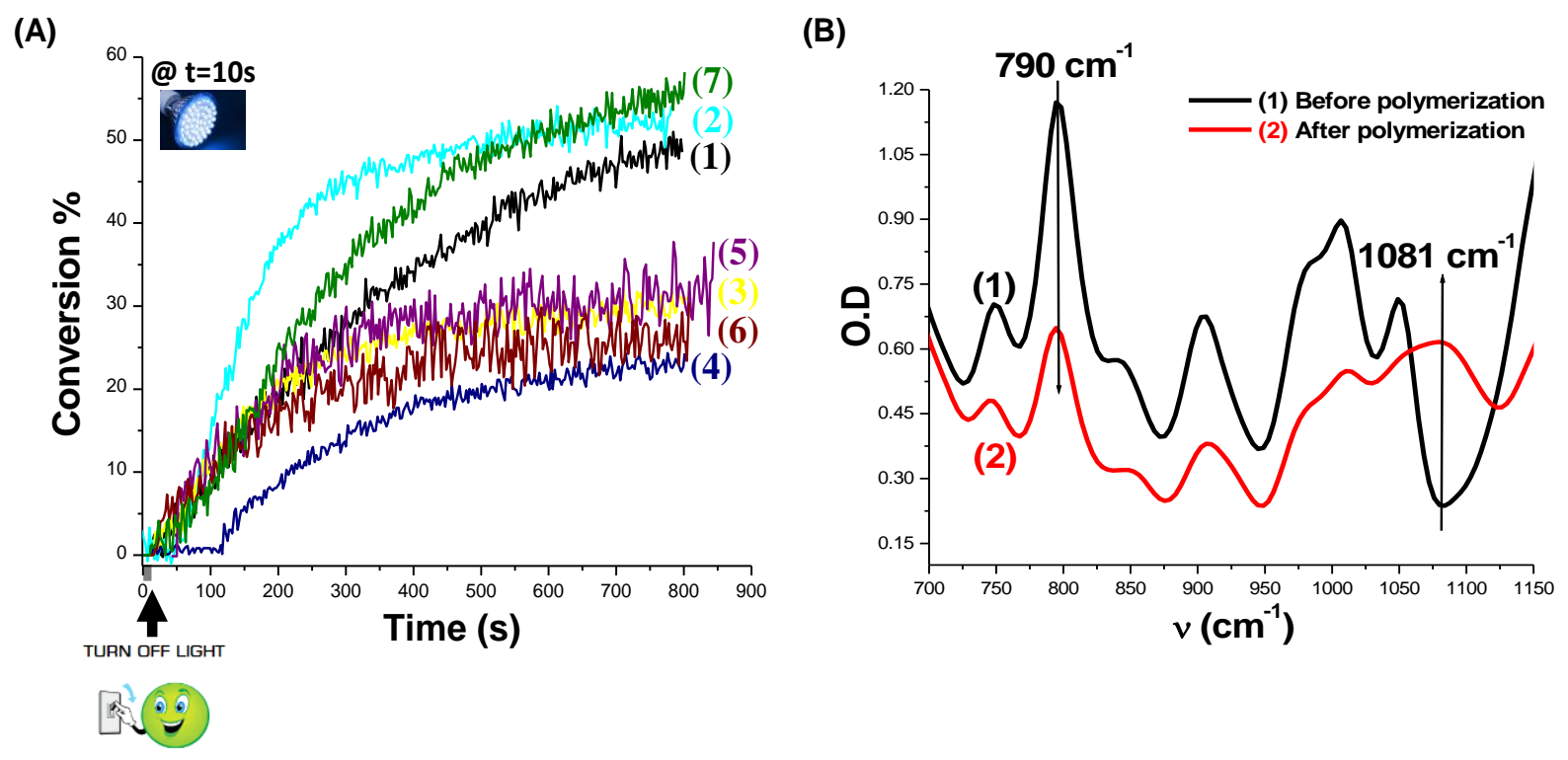

Figure 3. (A): Polymerization profiles (epoxy function conversion vs. irradiation time) of $25 \mu \mathrm{m}$ thin epoxide films under air upon irradiation with the LED@405 nm using different twocomponent Coum/Iod (0.2\%/1\% w/w) photoinitiating systems: (1) A1/Iod; (2) T2/Iod; (3) T3/Iod; (4) T4/Iod; (5) T5/Iod; (6) M3/Iod; and (7) N1/Iod. The irradiation is launched for $\mathrm{t}=10 \mathrm{~s}$. (B): For the T2/Iod $(0.2 \% / 1 \% \mathrm{w} / \mathrm{w})$ : FTIR spectra before and after polymerization.

Table 2. Final Reactive Epoxy Function Conversion (FC in \%) for EPOX, in the presence of Different Two-component Coum/Iod (0.2\%/1\% w/w) Photoinitiating Systems after $800 \mathrm{~s}$ of Irradiation with the LED @ $405 \mathrm{~nm}$. 


\begin{tabular}{|c|c|c|c|c|c|c|}
\hline A1/lod & T2/lod & T3/lod & T4/lod & T5/lod & M3/ lod & N1/ lod \\
\hline 50 & 54 & 32 & 23 & 38 & 30 & 58 \\
\hline
\end{tabular}

\subsection{Free Radical Photopolymerization (FRP) of Acrylates (TMPTA)}

\subsubsection{First Family: Nitrocoumarins (CoumN: N1-N6)}

Currently, very high efficiencies in terms of final acrylate function conversions (FC) and also rates of polymerization (Rp) were observed for the FRP of thin TMPTA films $(25 \mu \mathrm{m}$; LED@405nm; in laminate) for CoumN/Iod, CoumN/NPG, CoumN/Iod/NPG or CoumN/EDB couples (Figures 4A, 4B, 4C and 4D, respectively). The final reactive acrylate function conversions (FC) are gathered in the Table 3. In these irradiation conditions, Nitrocoumarins, Iod, NPG or EDB alone were tested and no or very low polymerization occurs; only the two-component systems lead to good polymerization processes.

Furthermore, it is quite obvious from the results in Figure 4 (curve 2 in Figures 4A, 4B and 4D) that $\mathbf{N} \mathbf{2}$ shows a superior initiating ability compared to the other derivatives of this family. In fact, $\mathbf{N 2}$ shows a great efficiency to initiate the FRP of acrylates using two different approaches; a photo-oxidation process with an iodonium salt (Figure 4A) but also a process of photo-reduction with amine (NPG or EDB, Figures 4B and 4D, respectively).

In the same context, excellent polymerization profiles for the FRP of TMPTA in thick samples are also obtained when using the LED@ $405 \mathrm{~nm}$. The FRP of thick acrylate samples (1.4 $\mathrm{mm}$ ) under air is quite efficient using two and three-component photoinitiating systems based on 
CoumN/Iod, CoumN/NPG or CoumN/EDB couples $(0.2 \% / 1 \%$ w/w) and CoumN/Iod/NPG $(0.2 \% / 1 \% / 1 \%$ w/w) combinations, upon irradiation with the LED@ $405 \mathrm{~nm}$ (Figure 5, Table 3) i.e. both high final reactive acrylate function conversions (FCs) for TMPTA and also high polymerization rates $(\mathrm{Rp})$ were achieved. Clearly, CoumN-based photoinitiating systems have the ability to surmount the oxygen inhibition observed for polymerization under air. Otherwise, it is clear that $\mathbf{N 2}$ shows a superiority over the other coumarin derivatives also for the FRP of thick samples. For this family, both the absorption properties and also the free energy changes of the electron transfer reaction provide the understanding of the efficiency of the involved systems (see below in the chemical mechanisms part).

When using these derivatives, a clear increase of the performance of the photoinitiating system is noted in the presence of NPG as a third component for the FRP of thin films e.g. for the $\mathrm{N} 1 /$ Iod/NPG system, the final acrylate function conversion achieved is about $52 \%$ compared to $22 \%$ for N1/Iod (curve (1) in Figure 4C vs. Figure 4A; Table 3). A similar behavior is also observed with the other derivatives (Figure 4C vs. Figure 4A; Table 3). In comparison, the two-component system Iod/NPG $(1 \% / 1 \% \mathrm{w} / \mathrm{w})$ shows a weak polymerization profile for the FRP of thin samples using the LED at $405 \mathrm{~nm}$ (Figure 4C, curve (7)), again suggesting the crucial role of Nitrocoumarins for the good performance of the system.

In addition, the good performance of the three-component systems CoumN/Iod/NPG $(0.2 \% / 1 \% / 1 \% \mathrm{w} / \mathrm{w})$ is also noted for thick samples i.e. the efficiency is increased to reach $82 \%$ with N6/Iod/NPG compared to N6/Iod for which no polymerization occurs (curve (6) in Figure 5C vs. Figure $5 \mathrm{~A}$; see Table 3$)$. Without dye, the Iod/NPG $(1 \% / 1 \% \mathrm{w} / \mathrm{w})$ system leads to a good polymerization profile for the FRP of thick samples (Figure 5C, curve (7)) but it exhibits a slower polymerization rate compared to those obtained by adding the coumarins $(\mathrm{FC}=84 \%, 84 \%, 83 \%$, 
$80 \%, 82 \% \& 82 \%$ for $\mathbf{N 1}, \mathbf{N 2}, \mathbf{N 3}, \mathbf{N} 4, \mathbf{N 5} \& \mathbf{N 6}$, respectively after 20s of irradiation compared to the Iod/NPG two-component system for which no polymerization has taken place (curves 1-6 vs. curve 7 in Figure $5 \mathrm{C}$ at $\mathrm{t}=20 \mathrm{~s}$, respectively).

Besides, some photos of TMTPA thick films $(1.4 \mathrm{~mm})$ before and after polymerization are represented in Figure S2 in SI using different two-component photoinitiating systems under air upon irradiation with the LED @ $405 \mathrm{~nm}$ for 100s. Note that the obtained thick polymers are tackfree and they also exhibit good bleaching properties during the polymerization (after irradiation).

(A)

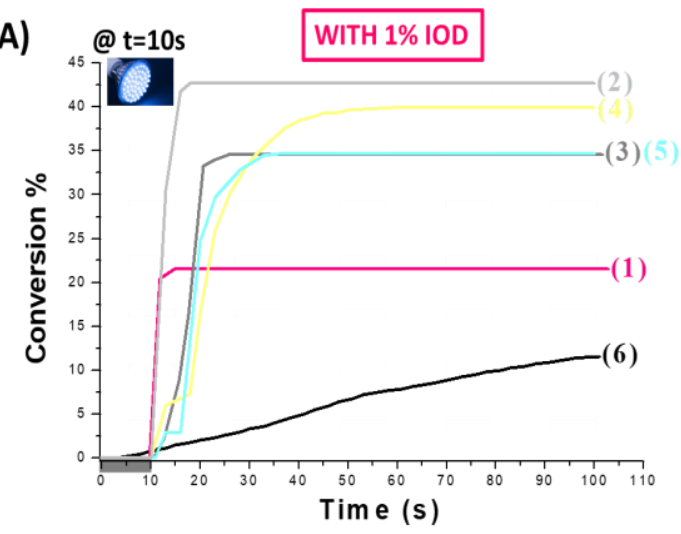

(C)

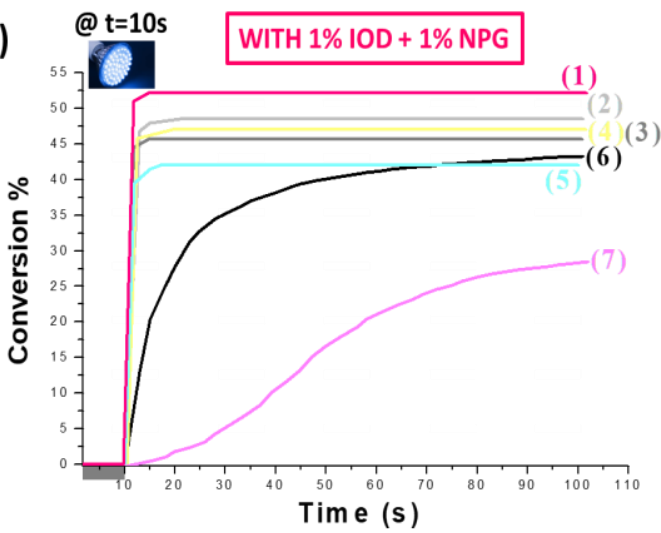

(B)

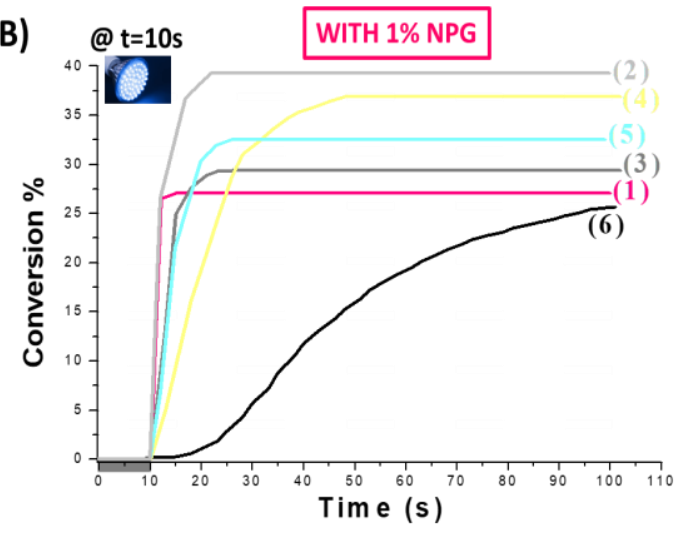

(D)

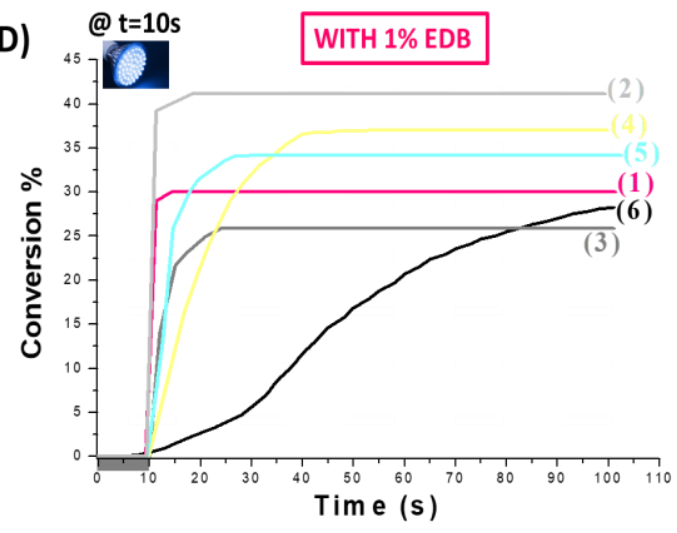

Figure 4. (A): Polymerization profiles (acrylate function conversion vs. irradiation time; LED@ $405 \mathrm{~nm})$ of thin $(25 \mu \mathrm{m})$ TMPTA films, in laminate for different two and three-component photoinitiating systems using Nitrocoumarins: (A): PI/Iod (0.2\%/1\% w/w), (B): PI/NPG $(0.2 \% / 1 \%$ w/w), (C): PI/Iod/NPG (0.2\%/1\%/1\% w/w), and (D): PI/EDB (0.2\%/1\% w/w): (1) $\mathrm{PI}=\mathrm{N1}$; (2) PI = N2; (3) PI = N3; (4) PI = N4; (5) PI = N5; (6) PI = N6; and (7) $\mathrm{Iod} / \mathrm{NPG}(1 \% / 1 \%$ $\mathrm{w} / \mathrm{w})((7)$ only for $\mathbf{C})$. The irradiation is launched for $\mathrm{t}=10 \mathrm{~s}$. 

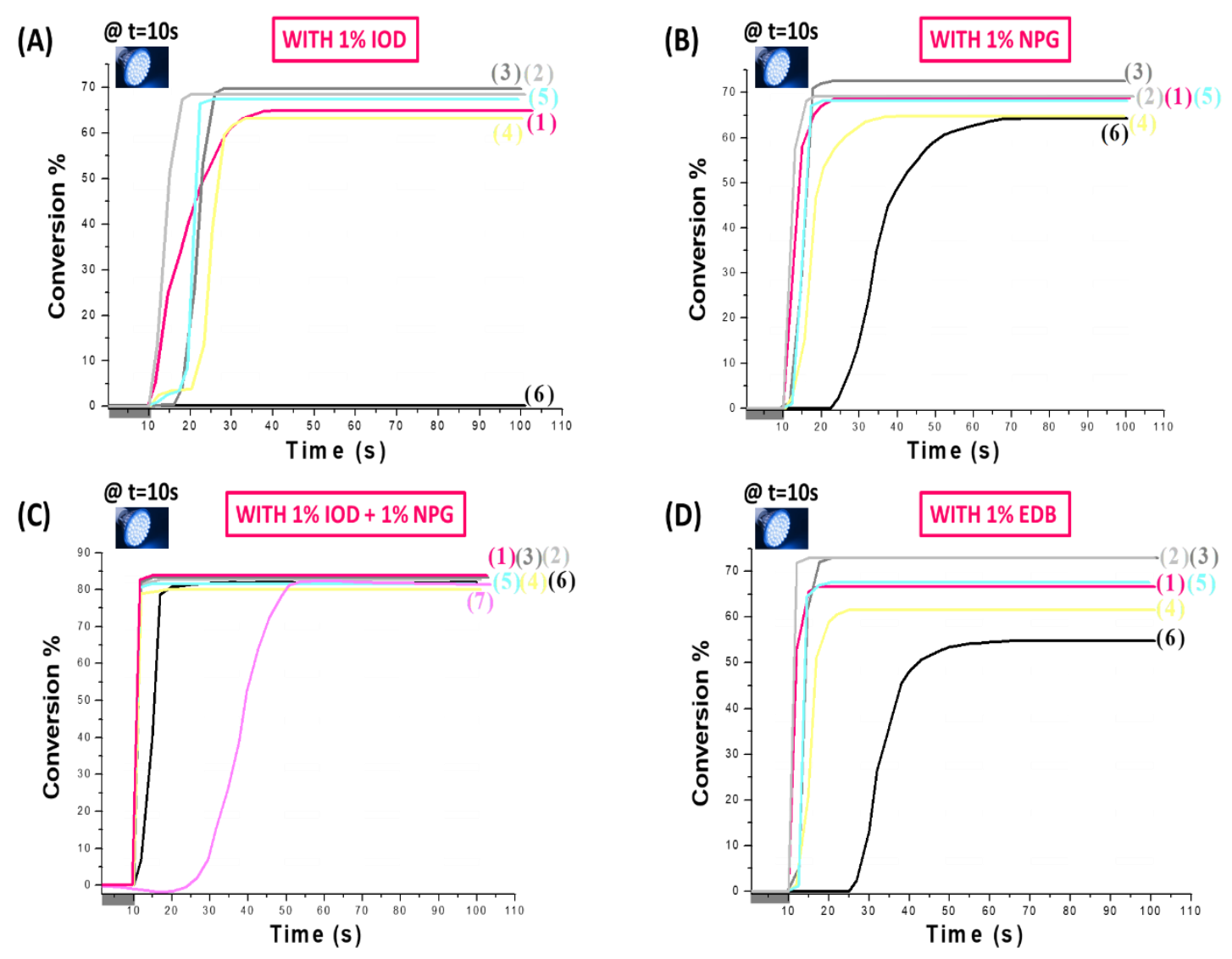

Figure 5. Polymerization profiles (acrylate function conversion vs. irradiation time) of $1.4 \mathrm{~mm}$ thick samples of TMPTA (under air, LED@405 nm) for different two and three-component photoinitiating systems using Nitrocoumarins: (A): PI/Iod (0.2\%/1\% w/w), (B): PI/NPG (0.2\%/1\% w/w), (C): PI/Iod/NPG (0.2\%/1\%/1\% w/w), and (D): PI/EDB (0.2\%/1\% w/w): (1) $\mathrm{PI}=\mathrm{N1}$; (2) PI = N2; (3) PI = N3; (4) PI = N4; (5) PI = N5; (6) PI = N6; and (7) Iod/NPG (1\%/1\% $\mathrm{w} / \mathrm{w})((7)$ only for $\mathbf{C})$. The irradiation is launched for $\mathrm{t}=10 \mathrm{~s}$. 


\subsubsection{Second Family: Methoxybenzene-based coumarins and Ethoxycoumarins (CoumM:}

M1-M6)

The final reactive acrylate function conversions (FCs) are gathered in the Table 3 and typical polymerization profiles are given in Figures $6 \mathrm{~A}, 6 \mathrm{~B}, 7 \mathrm{~A} \&$ 7B. In fact, the FRP of TMPTA in thin films $(25 \mu \mathrm{m})$, in laminate and in the presence of the M3/Iod or M3/Iod/NPG combinations (Table 3) is quite efficient upon irradiation with the LED @ $405 \mathrm{~nm}$. Note that Methoxybenzene-based coumarins, Ethoxycoumarin, Iod, NPG or EDB alone can't initiate the photopolymerization reaction under the same irradiation conditions.

In the presence of the iodonium, only M3 is able to initiate the FRP of thin acrylate films (Table 3), suggesting that only M3 is effective for a photo-oxidation process. However, all this series is almost not effective (very weak polymerization was showed for $\mathbf{M 3} /$ Iod with very low polymerization rate and $\mathrm{FC}=46 \%)$ to initiate the FRP of TMPTA in thick samples $(1.4 \mathrm{~mm}$, under air, LED @ $405 \mathrm{~nm}$ ). This can be probably related to the oxygen inhibition usually observed for FRP done under air, which levels off the performance of the system.

When replacing Iod by NPG or EDB, only M3 (or M4)/NPG (Curves (3) \& (4) in Figures $6 \mathrm{~A} \& 7 \mathrm{~A}$ for thin and thick samples, respectively) and M4/EDB (Curves (7) in Figures 6A \& 7A for thin and thick samples, respectively) show good polymerization profiles upon irradiation with the LED @405 nm for the FRP of TMPTA; this shows that M3 and M4 are excellent photoinitiators in the presence of amine.

Taking into account the three-component photoinitiating systems, the addition of the amine (NPG) leads to an increase in the performance in terms of FCs but also of polymerization rates i.e. $\mathrm{FC}=55 \%$ for M3/Iod/NPG $(0.2 \% / 1 \% / 1 \% \mathrm{w} / \mathrm{w})$ system (curve (3) in Figure $6 \mathrm{~B})$ after $15 \mathrm{~s}$ of 
irradiation compared to $\mathbf{M 3} / \mathrm{Iod}(0.2 \% / 1 \%$ w/w), for which no polymerization occurs. A similar great performance is also noticed with the other derivatives (Figure 6B; Table 3) compared to the non-efficiency of the two-component CoumM/Iod systems. Note that the two-component system Iod/NPG $(1 \% / 1 \% \mathrm{w} / \mathrm{w})$ shows low initiating ability for FRP of thin samples upon irradiation with a LED at $405 \mathrm{~nm}$ (Figure 6B, curve (7)), showing the huge role of these Methoxybenzene-based coumarins and Ethoxycoumarin derivatives.

Moreover, a very high efficiency was observed for these three-component systems CoumM/Iod/NPG $(0.2 \% / 1 \% / 1 \%$ w/w) for the FRP of thick TMPTA samples e.g. FC increases up to $85 \%$ with M4/Iod/NPG (curve (4) in Figure 7B) after 15s of irradiation compared to M4/Iod for which no polymerization could be detected. In comparison, the two-component system Iod/NPG $(1 \% / 1 \% \mathrm{w} / \mathrm{w})$ shows a low rate of polymerization compared to those obtained by adding the coumarin derivatives ( $\mathrm{FC}=85 \%$ for $\mathbf{M 4}$, and $83 \%$ for the other derivatives, respectively after $30 \mathrm{~s}$ of irradiation compared to Iod/NPG $(1 \% / 1 \% \mathrm{w} / \mathrm{w})$ for which no polymerization occurs (curves 1 6 for M1-M6 vs. curve 7 in Figure 7B at $\mathrm{t}=30$ s, respectively)), again highlighting the crucial role of these derivatives to generate high- performance systems.

Remarkably, tack-free polymers are obtained for these samples and the color of the obtained thick polymers remains light colored. No strong yellowing is observed in the presence of these Methoxybenzene-based coumarins and Ethoxycoumarin derivatives (some photos of TMTPA thick films (1.4 mm, under air, LED @ $405 \mathrm{~nm})$ after polymerization are shown in Figure S3 in SI for different photoinitiating systems).

\subsubsection{Third Family: Thiophene-based coumarins (CoumT: T1-T6)}


Typical polymerization profiles for Thiophene-based coumarins photoinitiating systems are presented in Figures 6C, 6D, 7C \& 7D, and the FCs are gathered in Table 3. Using the LED at 405 $\mathrm{nm}$ as a convenient mild irradiation source, the FRP of TMPTA in thin films ( $25 \mu \mathrm{m}$, in laminate), in the presence of the $\mathbf{T} 3 /$ Iod or $\mathbf{T} 3 /$ Iod/NPG combinations exhibits good efficiencies (Table 3). In addition, for Thiophene-based coumarins, Iod or NPG alone, no or very low polymerization occurs highlighting the role of these two or three-component systems for good initiating ability.

In addition, the experimental results show that only $\mathbf{T 3}$ and $\mathbf{T 6}$ are effective for a photooxidation process using iodonium salt as an additive. Note that $\mathbf{T 3}$ leads to higher FC compared to T6; this higher initiating ability of $\mathbf{T 3}$ can be probably related to its better absorption property at $405 \mathrm{~nm}\left(\boldsymbol{\varepsilon}_{(\mathbf{T} 3)}=7710 \mathrm{M}^{-1} \cdot \mathrm{cm}^{-1}\right.$ compared to $\boldsymbol{\varepsilon}_{(\mathbf{T} 6)}=940 \mathrm{M}^{-1} \cdot \mathrm{cm}^{-1} @ 405 \mathrm{~nm}$; Table 1).

For this family, the oxygen inhibition time avoids the initiation of the FRP of TMPTA in thick samples (1.4 mm, under air, LED @ $405 \mathrm{~nm}$ ) in the presence of the CoumT/Iod systems (very low polymerization was noted for $\mathbf{T} 1 /$ Iod with very low polymerization rate and $\mathrm{FC}=34 \%$ ). This can be tentatively assigned to their low initiating radical yields that are not able to overcome the oxygen inhibition.

Using CoumT/NPG (or EDB) $(0.2 \% / 1 \%$ w/w), only T6/NPG (or EDB) system efficiently initiates the FRP of TMPTA (thin and thick samples) upon exposure to the LED @ $405 \mathrm{~nm}$ (curves (6) and (7) in Figures 6C for thin films \& 7C for thick samples, respectively) showing that $\mathbf{T 6}$ is a good Type II photoinitiator in the presence of amine. Therefore, a higher electron transfer yield can be expected with T6 compared to the other derivatives of this family, leading to a higher initiating radical yield. 
In fact, after the addition of an amine (NPG) as a third component, the FCs of TMPTA (for thin films) increased for the CoumT/Iod/NPG $(0.2 \% / 1 \% / 1 \% \mathrm{w} / \mathrm{w})$ three-component PISs using the LED @ $405 \mathrm{~nm}$ e.g. FC increases up to 51\% with T3/Iod/NPG (curve (3) in Figure 6D) compared to only $33 \%$ with T4/Iod after 30s of irradiation. A similar behavior is also remarked with the other derivatives (Figure 6D; Table 3) compared to the two-component CoumT/Iod PISs for which no polymerization occurs.

This enhancement is also observed for the FRP of TMPTA in thick samples when using the LED @ $405 \mathrm{~nm}$ i.e. the efficiency rises up to attain $83 \%$ for T6/Iod/NPG $(0.2 \% / 1 \% / 1 \%$ w/w) (curve (6) in Figure 7D) after 30s of irradiation compared to T6/Iod $(0.2 \% / 1 \%$ w/w), for which no polymerization has been produced. The presence of coumarins is important for the global performance i.e. the Iod/NPG $(1 \% / 1 \% \mathrm{w} / \mathrm{w})$ system leads to a poorer polymerization profile for the FRP of thick samples (Figure 7D, curve (7)).

In addition, tack-free polymers are obtained when using Thiophene-based coumarins as PIs, no strong yellowing is observed in the presence of these derivatives (photos before and after polymerization of TMTPA in thick films $(1.4 \mathrm{~mm})$ under air are given in Figure S4 in SI using different two and three-component PISs upon exposure to the LED @ $405 \mathrm{~nm}$ ). 

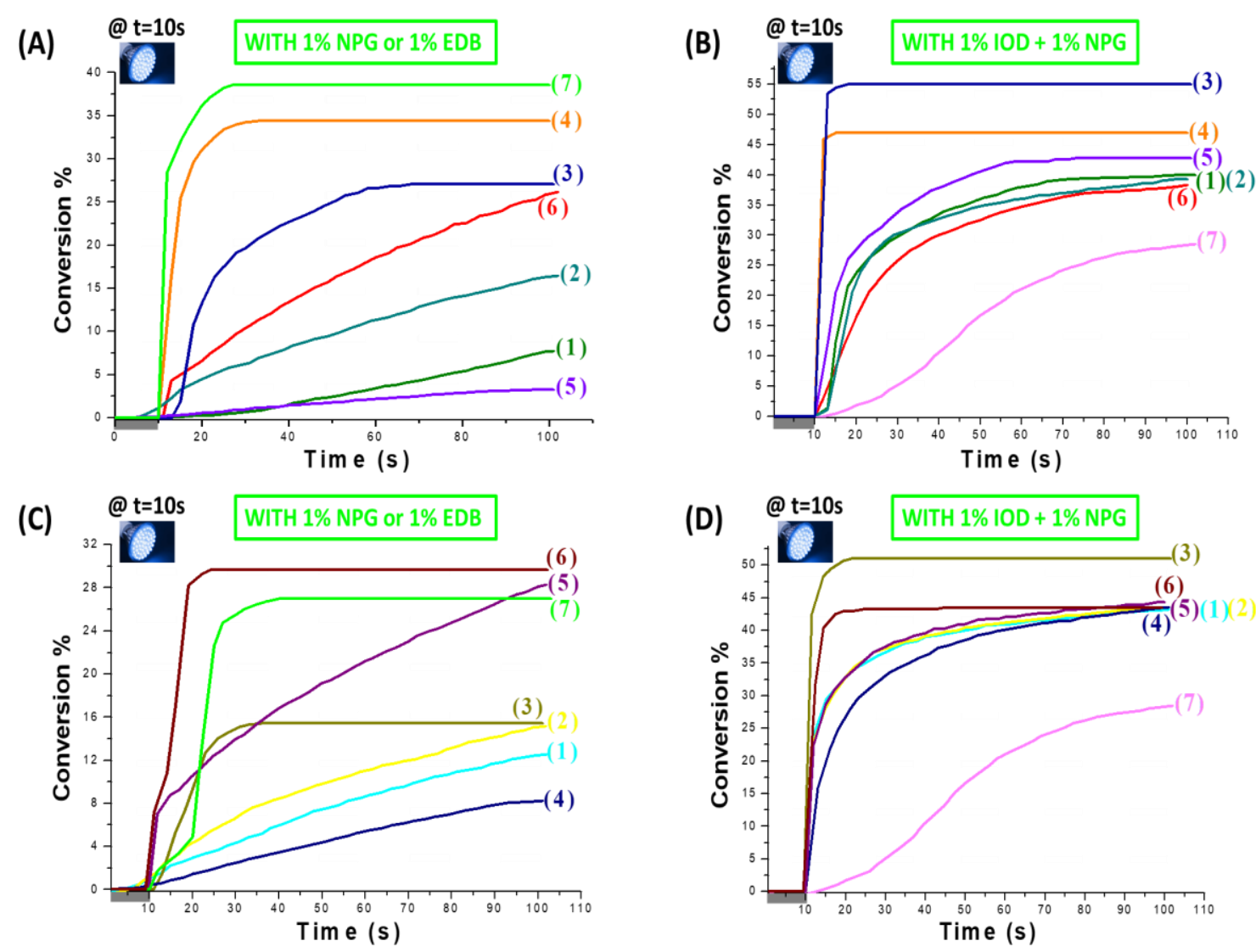

Figure 6. (A): Polymerization profiles (acrylate function conversion vs. irradiation time) of thin $(25 \mu \mathrm{m})$ TMPTA films, in laminate upon irradiation with the LED@405 nm in the presence of different two and three-component photoinitiating systems using (A) and (B): Methoxybenzenebased coumarins and Ethoxycoumarins or (C) and (D): Thiophene-based coumarins: (A): PI/NPG (or EDB) (0.2\%/1\% w/w): (1) M1/NPG; (2) M2/NPG; (3) M3/NPG; (4) M4/NPG; (5) M5/NPG; (6) M6/NPG; and (7) M4/EDB. (B): PI/Iod/NPG (0.2\%/1\%/1\% w/w): (1) M1/Iod/NPG; (2) M2/Iod/NPG; (3) M3/Iod/NPG; (4) M4/Iod/NPG; (5) M5/Iod/NPG; (6) M6/Iod/NPG; and (7) Iod/NPG (1\%/1\% w/w). (C): PI/NPG (or EDB) (0.2\%/1\% w/w): (1) T1/NPG; (2) T2/NPG; (3) T3/NPG; (4) T4/NPG; (5) T5/NPG; (6) T6/NPG; and (7) T6/EDB. (D): PI/Iod/NPG (0.2\%/1\%/1\% w/w): (1) T1/Iod/NPG; (2) T2/Iod/NPG; (3) T3/Iod/NPG; (4) T4/Iod/NPG; (5) T5/Iod/NPG; (6) T6/Iod/NPG; and (7) Iod/NPG (1\%/1\% w/w). The irradiation is launched for $\mathrm{t}=$ $10 \mathrm{~s}$. 

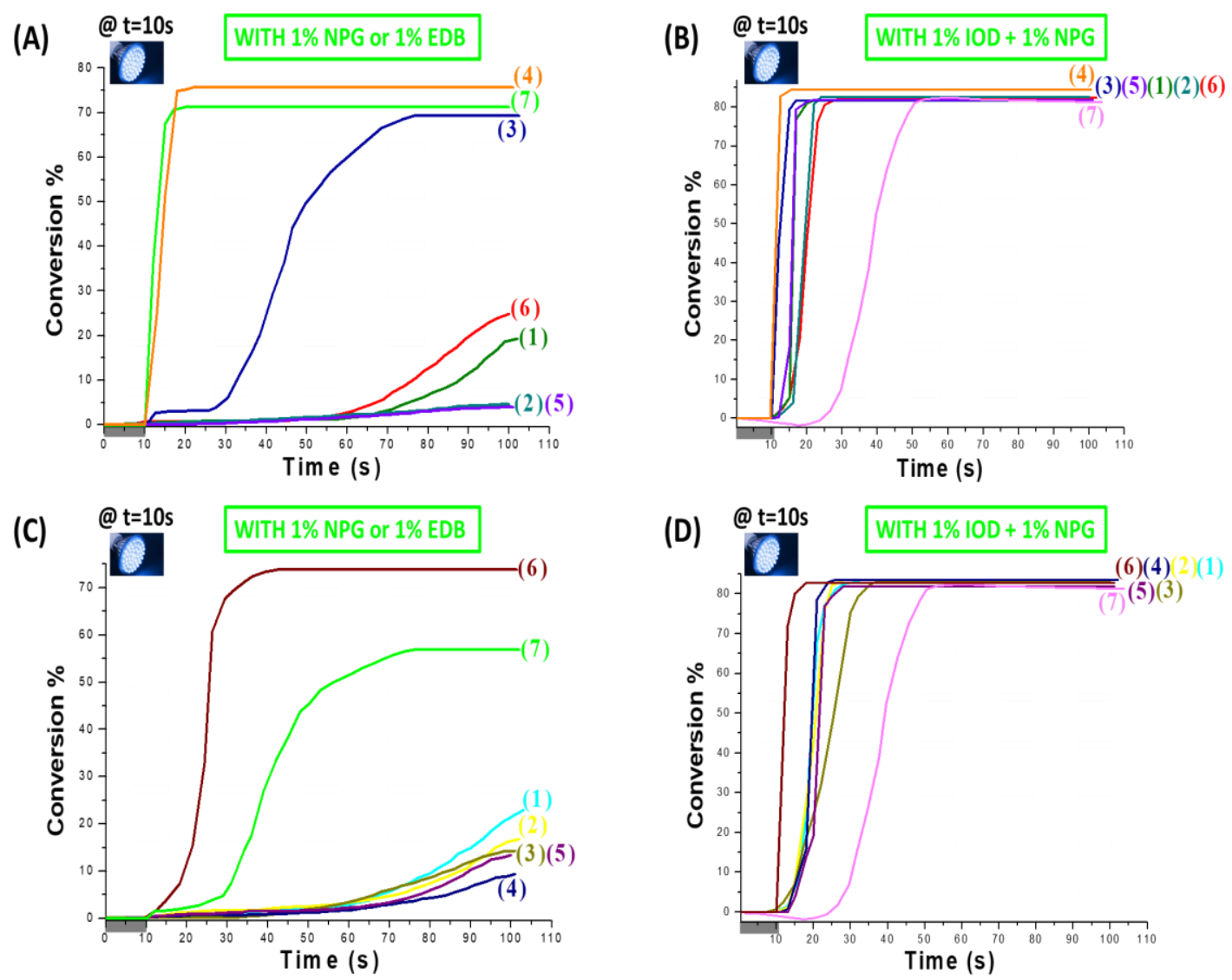

Figure 7. Polymerization profiles (acrylate function conversion vs. irradiation time) of $1.4 \mathrm{~mm}$ thick samples of TMPTA (under air, using LED@405 nm) in the presence of different two and three-component photoinitiating systems using (A) and (B): Methoxybenzene-based coumarins and Ethoxycoumarins or (C) and (D): Thiophene-based coumarins: (A): PI/NPG (or EDB) (0.2\%/1\% w/w): (1) M1/NPG; (2) M2/NPG; (3) M3/NPG; (4) M4/NPG; (5) M5/NPG; (6) M6/NPG; and (7) M4/EDB. (B): PI/Iod/NPG (0.2\%/1\%/1\% w/w): (1) M1/Iod/NPG; (2) M2/Iod/NPG; (3) M3/Iod/NPG; (4) M4/Iod/NPG; (5): M5/Iod/NPG; (6) M6/Iod/NPG; and (7) Iod/NPG (1\%/1\% w/w). (C): PI/NPG (or EDB) (0.2\%/1\% w/w): (1) T1/NPG; (2) T2/NPG; (3) T3/NPG; (4) T4/NPG; (5) T5/NPG; (6) T6/NPG; and (7) T6/EDB. (D): PI/Iod/NPG (0.2\%/1\%/1\% w/w): (1) T1/Iod/NPG; (2) T2/Iod/NPG; (3) T3/Iod/NPG; (4) T4/Iod/NPG; (5) T5/Iod/NPG; (6) T6/Iod/NPG; and (7) Iod/NPG (1\%/1\% w/w). The irradiation is launched for $\mathrm{t}=$ $10 \mathrm{~s}$.

\subsubsection{Fourth Family: Alkyne-based coumarin (CoumA1)}

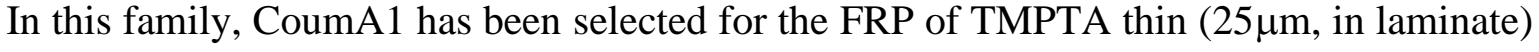
and thick (1.4 mm, under air) samples using the LED @ $405 \mathrm{~nm}$ in the presence of two and three- 
component photoinitiating systems based on CoumA1/Iod, CoumA1/NPG or CoumA1/EDB couples $(0.2 \% / 1 \% \mathrm{w} / \mathrm{w})$ and CoumA1/Iod/NPG combination $(0.2 \% / 1 \% / 1 \% \mathrm{w} / \mathrm{w})$, respectively (Figure S5A for thin samples and Figure S5B for thick samples).

In fact, the two-component PISs (CoumA1/Iod, CoumA1/NPG and CoumA1/EDB) are not able to initiate the FRP thin and thick samples of acrylates under exposure to the LED @ $405 \mathrm{~nm}$, showing that CoumA1 is probably a poor photoinitiator in both photo-oxidation (CoumA1/Iod) but also in photo-reduction processes (CoumA1/Amine).

While, the good performance of CoumA1 is only observed for three-component systems, the CoumA1/Iod/NPG $(0.2 \% / 1 \% / 1 \% \mathrm{w} / \mathrm{w})$ combination efficiently initiate the FRP of TMPTA in thin and thick films (curve (3) in Figure S5A and S5B, respectively). FC reached was about 40\% with CoumA1/Iod/NPG (thin films) compared to CoumA1/Iod, for which no polymerization occurs (Figure S5A: curve (3) vs. curve (1), respectively; Table 3). For thick samples, FC = 77\% with CoumA1/Iod/NPG vs. CoumA1/Iod, for which no polymerization has taken place (Figure S5B: curve (3) vs. curve (1), respectively; Table 3). This shows that the presence of an amine (NPG) in a three-component system drastically increases the photoinitiating ability. Furthermore, the final obtained thick polymers are tack-free and without residual color (photos before and after polymerization are presented in Figure S6 in SI). 
Table 3. Final Reactive Acrylate Function Conversion (FC in \%) for TMPTA, in the presence of Different Two $(0.2 \% / 1 \% \mathrm{w} / \mathrm{w})$ and Three-component $(0.2 \% / 1 \% / 1 \% \mathrm{w} / \mathrm{w})$ Photoinitiating

Systems after 100s of Irradiation with LED @ $405 \mathrm{~nm}$.

\begin{tabular}{|c|c|c|c|c|c|c|c|c|c|}
\hline & & \multicolumn{8}{|c|}{ Final Reactive Acrylate Function Conversion (FC\%) for TMPTA } \\
\hline & & \multicolumn{4}{|c|}{ Thin sample $(25 \mu \mathrm{m})$ in laminate } & \multicolumn{4}{|c|}{ Thick sample (1.4 mm) under air } \\
\hline & & \multicolumn{3}{|c|}{ Two-component PIS } & \multirow{2}{*}{$\begin{array}{c}\text { Three- } \\
\text { component } \\
\text { PIS } \\
+ \text { lod/NPG }\end{array}$} & \multicolumn{3}{|c|}{ Two-component PIS } & \multirow{2}{*}{$\begin{array}{c}\begin{array}{c}\text { Three- } \\
\text { component } \\
\text { PIS }\end{array} \\
\text { +lod/NPG }\end{array}$} \\
\hline & & + lod & +NPG & +EDB & & + lod & + NPG & +EDB & \\
\hline \multirow{6}{*}{$\begin{array}{l}\text { First Family: } \\
\text { Nitrocoumarins }\end{array}$} & N1 & 22 & 27 & 30 & 52 & 65 & 69 & 67 & 84 \\
\hline & N2 & 43 & 40 & 41 & 49 & 69 & 70 & 73 & 83 \\
\hline & N3 & 35 & 30 & 26 & 46 & 70 & 73 & 73 & 83 \\
\hline & N4 & 40 & 37 & 37 & 47 & 64 & 65 & 62 & 81 \\
\hline & N5 & 35 & 33 & 34 & 42 & 68 & 69 & 68 & 82 \\
\hline & N6 & n.p. & 26 & 28 & 44 & n.p. & 65 & 55 & 82 \\
\hline \multirow{6}{*}{$\begin{array}{l}\text { Second Family: } \\
\text { Methoxybenzene- } \\
\text { based coumarins } \\
\text { and } \\
\text { Ethoxycoumarins }\end{array}$} & M1 & n.p. & n.p. & n.p. & 40 & n.p. & n.p. & n.p. & 83 \\
\hline & M2 & n.p. & n.p. & n.p. & 40 & n.p. & n.p. & n.p. & 83 \\
\hline & M3 & 40 & 27 & n.p. & 55 & 46 & 69 & n.p. & 83 \\
\hline & M4 & n.p. & 35 & 39 & 47 & n.p. & 76 & 72 & 85 \\
\hline & M5 & n.p. & n.p. & n.p. & 43 & n.p. & n.p. & n.p. & 82 \\
\hline & M6 & n.p. & n.p. & n.p. & 39 & n.p. & n.p. & 74 & 83 \\
\hline \multirow{2}{*}{$\begin{array}{c}\text { Third Family: } \\
\text { Thiophene-based } \\
\text { coumarins }\end{array}$} & T1 & n.p. & n.p. & n.p. & 44 & 34 & n.p. & n.p. & 83 \\
\hline & T2 & n.p. & n.p. & n.p. & 44 & n.p. & n.p. & n.p. & 84 \\
\hline
\end{tabular}




\begin{tabular}{|c|c|c|c|c|c|c|c|c|c|}
\hline & T3 & 33 & n.p. & n.p. & 51 & n.p. & n.p. & n.p. & 83 \\
\hline & T4 & n.p. & n.p. & n.p. & 44 & n.p. & n.p. & n.p. & 84 \\
\hline & T5 & n.p. & n.p. & n.p. & 44 & n.p. & n.p. & n.p. & 82 \\
\hline & T6 & 23 & 30 & 27 & 44 & n.p. & $74 \%$ & $57 \%$ & 83 \\
\hline $\begin{array}{c}\text { Fourth Family: } \\
\text { Alkyne-based } \\
\text { coumarin }\end{array}$ & A1 & n.p. & n.p. & n.p. & 40 & n.p. & n.p. & n.p. & 77 \\
\hline
\end{tabular}

n.p.: no polymerization

\subsection{Free radical photopolymerization of methacrylates (BisGMA/TEGDMA)}

\subsubsection{First Family: Nitrocoumarins (CoumN: N1-N6)}

In this paragraph, a comparative study for the different CoumN/Iod, CoumN/NPG or CoumN/EDB $(0.2 \% / 1 \%$ w/w $)$ couples and CoumN/Iod/NPG $(0.2 \% / 1 \% / 1 \%$ w/w $)$ combinations is given for the FRP of a benchmarked methacrylate system (BisGMA/TEGDMA 70\%/30\% w/w).

Interestingly, the two and three-component photoinitiating systems using Nitrocoumarins showed a great efficiency to initiate the FRP of BisGMA/TEGDMA blend in thick samples (1.4 mm) under air upon exposure to the LED @ 405 nm (Figure 8; Table 4). Indeed, oxygen inhibition is usually observed in FRP under air whereas these PISs involving Nitrocoumarins are clearly extremely efficient photoinitiators to beat this inhibition. Typical polymerization profiles (methacrylate function conversion vs. time) are depicted in Figure 8 and the FCs are gathered in the Table 4. As expected, Iod alone is not able to initiate the FRP of methacrylate in line with its lack of absorption for $\lambda>300 \mathrm{~nm}$. The same remark is true for NPG, EDB or Nitrocoumarins 
alone, highlighting the requirement to mix these different derivatives to access to efficient photoinitiating systems.

In fact, the majority of Nitrocoumarins (N1-N5) are excellent photoinitiators in combination with an iodonium salt as an additive to initiate the FRP of thick methacrylate samples through a photo-oxidation process as shown in Figure 8A (see also in Table 4). N1/Iod system leads to both the highest FC and Rp (curve (1) in Figure 8A; Table 4). This latter behavior can be attributed to its highest absorption property (@ $405 \mathrm{~nm})$ that distinguishes $\mathbf{N 1}\left(\boldsymbol{\varepsilon}_{(\mathbf{N} 1)}=9750 \mathrm{M}^{-1} \cdot \mathrm{cm}^{-1}\right.$ compared to the other derivatives @ $405 \mathrm{~nm}$; Table 1). In addition, the non-efficiency of N6/Iod system can be probably ascribed to its lowest absorption properties at $405 \mathrm{~nm}\left(\boldsymbol{\varepsilon}(\mathrm{N} 6)=145 \mathrm{M}^{-1}\right.$. $\mathrm{cm}^{-1}$; Table 1).

Furthermore, all Nitrocoumarins (N1-N6) show a huge efficiency to initiate the FRP of methacrylates according to a photo-reduction process using an amine (NPG or EDB) as evidenced in Figures 8B \& 8D, respectively (Table 4). It is well obvious that the N2/NPG (or EDB) couples exhibit the best efficiencies over all the other derivatives; they show both highest Rp and FC when using the LED @ 405 nm (curve (2) vs. curves (1,3-6) in Figure 8B with NPG as an additive and Figure 8D with EDB as an additive; Table 4). This shows that $\mathbf{N 2}$ is more efficient as a Type II photoinitiator, suggesting a more favorable reduction process by amine.

For the three-component systems CoumN/Iod/NPG $(0.2 \% / 1 \% / 1 \% \mathrm{w} / \mathrm{w})$, the addition of the amine (NPG) as a hydrogen donor results in a noticeable increase in the performance of the system in terms of Rps and FCs (Figure 8C) e.g. a final conversion up to 84\% is obtained with N1/Iod/NPG after 15 s of irradiation instead of only $13 \%$ with N1/Iod (curve (1) in Figure 8C vs. Figure 8A, respectively; Table 4). Remarkably, colorless tack-free polymers have been obtained (see Figure S7). 

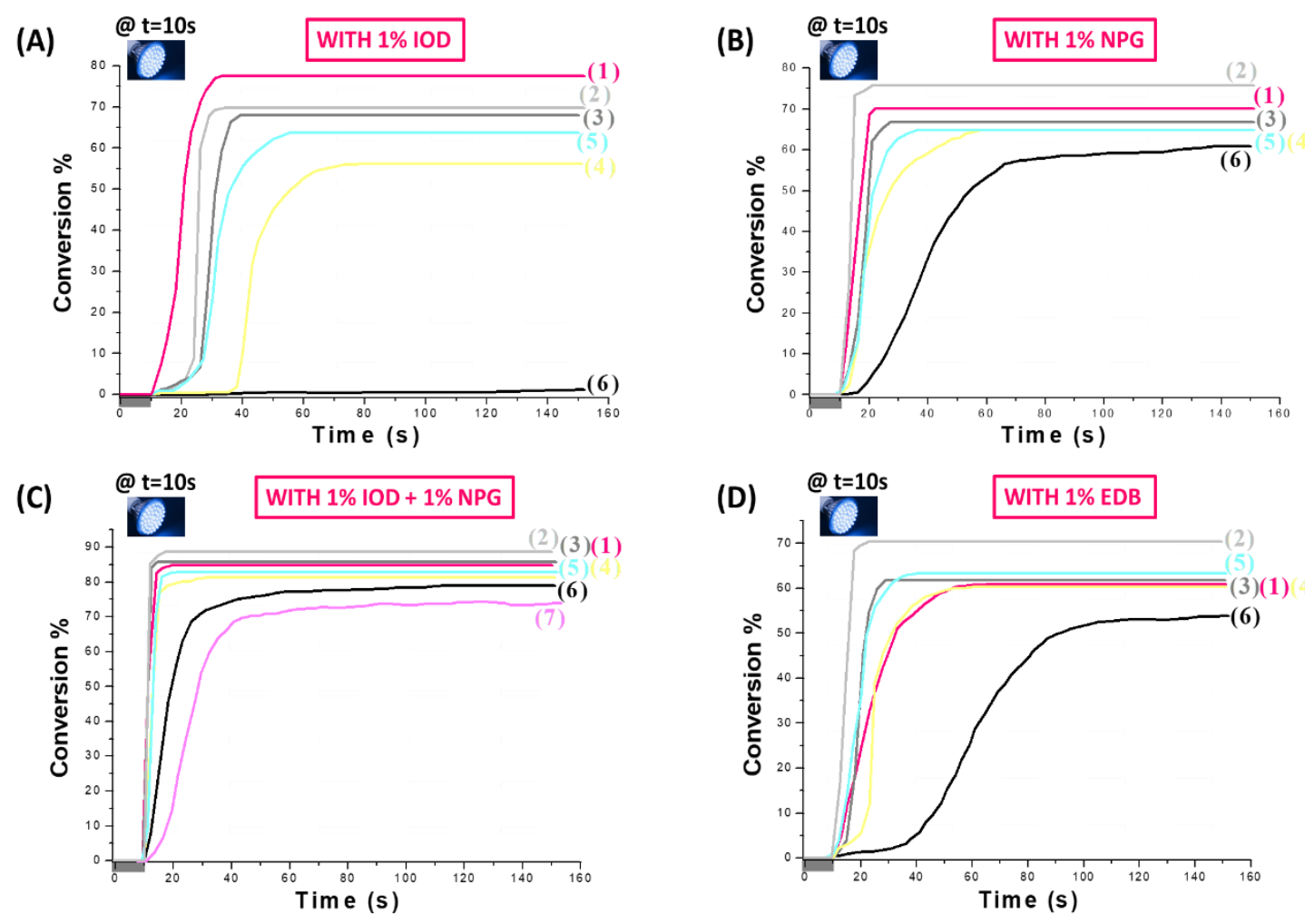

Figure 8. Polymerization profiles (methacrylate function conversion vs. irradiation time) of 1.4 mm thick samples of BisGMA/TEGDMA blend (under air, using LED@ $405 \mathrm{~nm}$ ) in the presence of different two and three-component photoinitiating systems using Nitrocoumarins: (A): PI/Iod (0.2\%/1\% w/w), (B): PI/NPG (0.2\%/1\% w/w), (C): PI/Iod/NPG (0.2\%/1\%/1\% w/w), and (D): PI/EDB (0.2\%/1\% w/w): (1) PI = N1; (2) PI = N2; (3) PI = N3; (4) PI = N4; (5) PI = N5; (6) PI = N6; and (7) Iod/NPG $(1 \% / 1 \% \mathrm{w} / \mathrm{w})((7)$ only for $\mathbf{C})$. The irradiation is launched for $\mathrm{t}=10 \mathrm{~s}$.

\subsubsection{Second Family: Methoxybenzene-based coumarins and Ethoxycoumarins (CoumM:}

\section{M1-M6)}

Typical polymerization profiles using Methoxybenzene-based coumarins and Ethoxycoumarin derivatives in PISs are presented in Figures 9A \& 9B and the FCs are gathered in the Table 4. In an interesting way, M4/NPG $(0.2 \% / 1 \%$ w/w $)$ system could efficiently initiate the FRP of methacrylate monomers (BisGMA/TEGDMA 70\%/30\% w/w) (under air, $1.4 \mathrm{~mm}$ thick sample, irradiation with the LED @ 405 nm) (curve (4) in Figure 9A). This good performance is 
also observed with the other Methoxybenzene-based coumarins and Ethoxycoumarin derivatives but with a slight inhibition time for the polymerization under air. This shows that M4 exhibits a better efficiency over the other CoumM/NPG systems (Figure 9A: curve (4) vs. curves (1-3,5,6); Table 4). Furthermore, M4 is the only one able to initiate the FRP of methacrylates in combination with EDB as an additive through a photo-reduction process (Figure 9A: curve (7)). All these results show that M4 is very efficient as a Type II photoinitiator.

On the other hand, CoumM/Iod $(0.2 \% / 1 \% \mathrm{w} / \mathrm{w})$ systems are not able to initiate the FRP thick samples of methacrylates under air upon irradiation with the LED@ 405 nm (only M4 is able to weakly initiate the reaction; Table 4). This can be probably attributed to their low initiating radical yields that are not able to overcome the oxygen inhibition.

Clearly, the three-component photoinitiating systems CoumM/Iod/NPG $(0.2 \% / 1 \% / 1 \%$ w/w $)$ using Methoxybenzene-based coumarins or Ethoxycoumarins (Figure 9B) have the ability to overcome the oxygen inhibition observed in the presence of the two-component (CoumM/Iod) PISs. For all this series of coumarins, colorless tack-free polymers have been obtained (Figure S8).

\subsubsection{Third Family: Thiophene-based coumarins (CoumT: T1-T6)}

The FRP of methacrylates (BisGMA/TEGDMA 70\%/30\% w/w) for thick samples $(1.4 \mathrm{~mm})$ is realized under air upon irradiation with the LED@405 nm in the presence of two (CoumT/Iod (or NPG or EDB) $(0.2 \% / 1 \%$ w/w)) and three-component (CoumT/Iod/NPG $(0.2 \% / 1 \% / 1 \%$ w/w)) photoinitiating systems using Thiophene-based coumarins (Figures 9C, 9D; Table 4). In the same irradiation conditions, Thiophene-based coumarins, Iod or NPG or EDB considered separately are not capable to initiate the FRP of methacrylates under air, showing that only multicomponent systems are efficient. 
Using CoumT/Iod $(0.2 \% / 1 \%$ w/w) systems, no efficiency was observed for the FRP of methacrylates under air when irradiated with the LED@ $405 \mathrm{~nm}$ (very weak polymerization was observed for $\mathbf{T} 3 /$ Iod with FC $<15 \%$ ). This behavior can be probably related to the oxygen inhibition time usually observed in FRP under air, showing that these compounds are poor photoinitiators in combination with an Iodonium salt.

While, these derivatives are good photoinitiators when combined with an amine (NPG), showing that CoumT/NPG systems are able to initiate the FRP thick samples of methacrylates under air using the LED @ 405 nm (Figure 9C). Remarkably, T6 can be selected as the best Type II photoinitiator among this series due to its highest performance as shown in Figure 9C (curve (6) vs. curves (1-5); see also in Table 4). This can be ascribed to the high initiating ability of T6 capable to overcome the oxygen inhibition.

Only T6/EDB $(0.2 \% / 1 \%$ w/w) system shows good polymerization profile (curve (7) in Figure 9C). The other Thiophene-based coumarins are poor photoinitiators when associated with EDB for a photoreduction process.

By testing the three-component photoinitiating systems CoumT/Iod/NPG $(0.2 \% / 1 \% / 1 \%$ w/w) (Figure 9D), it is obvious that they are very efficient to overcome the oxygen inhibition time which is observed when using the two-component (CoumT/Iod) PISs. For this series of coumarins, colorless tack-free polymers have been obtained (Figure S9). 

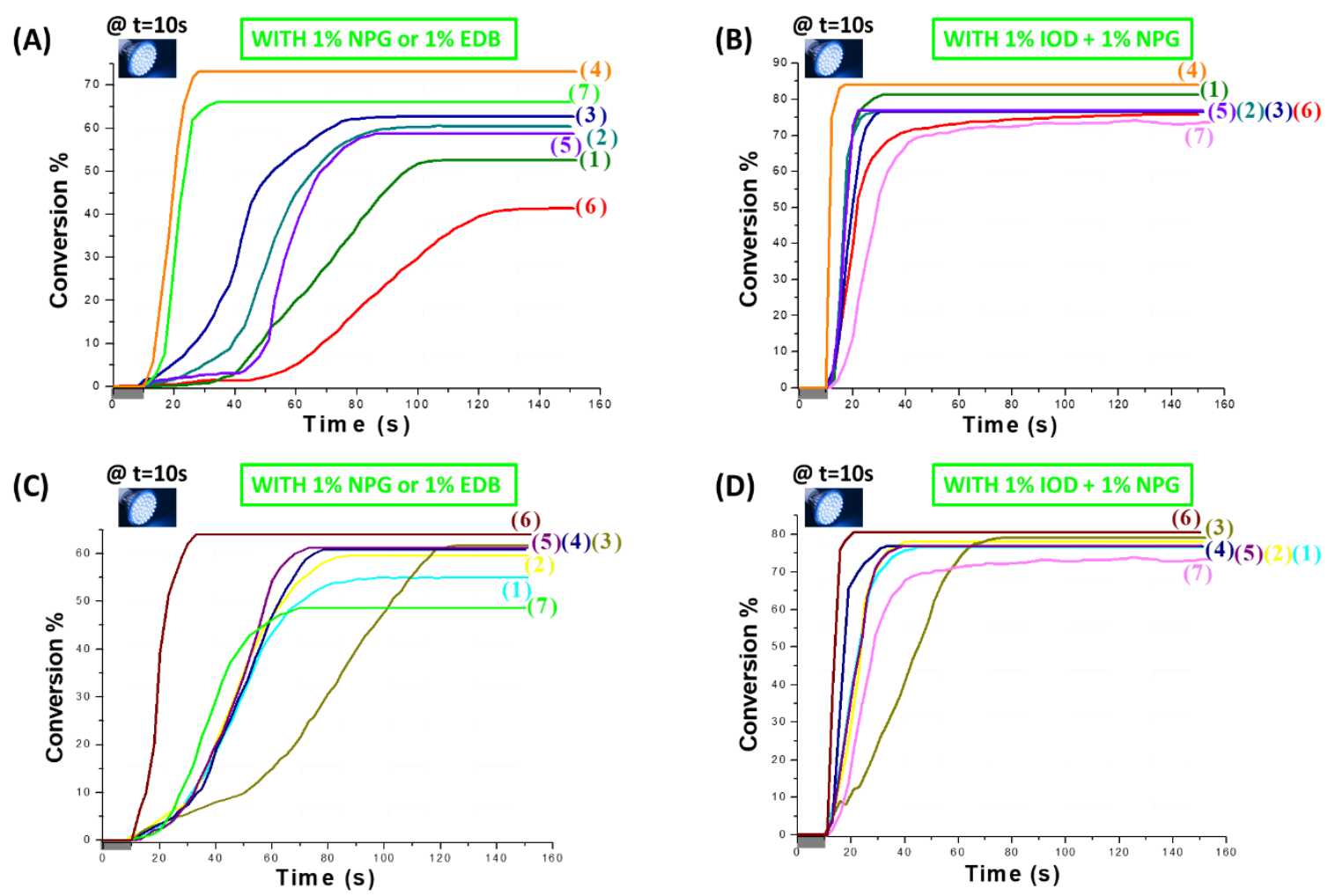

Figure 9. Polymerization profiles (methacrylate function conversion vs. irradiation time) of 1.4 mm thick samples of BisGMA/TEGDMA blend (under air, using LED@405 nm) in the presence of different two and three-component photoinitiating systems using (A) and (B): Methoxybenzene-based coumarins and Ethoxycoumarins or (C) and (D): Thiophene-based coumarins: (A): PI/NPG (or EDB) (0.2\%/1\% w/w): (1) M1/NPG; (2) M2/NPG; (3) M3/NPG; (4): M4/NPG; (5) M5/NPG; (6) M6/NPG; and (7) M4/EDB. (B): PI/Iod/NPG (0.2\%/1\%/1\% w/w): (1) M1/Iod/NPG; (2) M2/Iod/NPG; (3) M3/Iod/NPG; (4) M4/Iod/NPG; (5) M5/Iod/NPG; (6) M6/Iod/NPG; and (7) Iod/NPG (1\%/1\% w/w). (C): PI/NPG (or EDB) $(\mathbf{0 . 2 \% / 1 \%}$ w/w): (1) T1/NPG; (2) T2/NPG; (3) T3/NPG; (4) T4/NPG; (5) T5/NPG; (6) T6/NPG; and (7) T6/EDB. (D): PI/Iod/NPG (0.2\%/1\%/1\% w/w): (1) T1/Iod/NPG; (2) T2/Iod/NPG; (3) T3/Iod/NPG; (4) T4/Iod/NPG; (5) T5/Iod/NPG; (6) T6/Iod/NPG; and (7) Iod/NPG (1\%/1\% w/w). The irradiation is launched for $\mathrm{t}=10 \mathrm{~s}$.

\subsubsection{Fourth Family: Alkyne-based coumarin (CoumA1)}

In this part, two and three-component photoinitiating systems based on A1 (alkyne-based coumarin) were used for the FRP of BisGMA/TEGDMA blend (thickness $=1.4 \mathrm{~mm}$, under air) upon irradiation with the LED @ 405 nm (Figure S5C). 
The A1/Iod (or EDB) $(0.2 \% / 1 \% \mathrm{w} / \mathrm{w})$ couple shows no efficiency to initiate the FRP of methacrylates. Whereas, A1 is efficient for a photo-reduction process combined with NPG (A1/NPG $(0.2 \% / 1 \%$ w/w)) as shown in Figure S5C (curve 2).

For the three-component A1/Iod/NPG (0.2\%/1\%/1\% w/w) system, the addition of the amine (NPG) as a third component shows rather similar polymerization profile than the one obtained with the two-component system Iod/NPG (1\%/1\% w/w) (Figure S5C: curve (3) for A1 vs. curve (5) for Iod/NPG, respectively). As for the other series, colorless polymers are always obtained (photos before and after polymerization are depicted in Figure S6 in SI).

Table 4. Final Reactive Methacrylate Function Conversion (FC in \%) for a BisGMA/TEGDMA blend after $150 \mathrm{~s}$ of irradiation with the LED @ $405 \mathrm{~nm}$ using Different Two $(0.2 \% / 1 \%$ w/w) and Three-component $(0.2 \% / 1 \% / 1 \% \mathrm{w} / \mathrm{w})$ Photoinitiating Systems (under air; thickness $=1.4 \mathrm{~mm}$ ).

\begin{tabular}{|c|c|c|c|c|c|}
\cline { 3 - 6 } \multicolumn{2}{c|}{} & \multicolumn{4}{c|}{$\begin{array}{c}\text { Final Reactive Methacrylate Function Conversion (FC\%) for } \\
\text { BisGMA/TEGDMA Blend, Thick sample (1.4 mm) under air }\end{array}$} \\
\cline { 3 - 7 } & \multicolumn{3}{c|}{ Two-component PIS } & Three- \\
component PIS
\end{tabular}




\begin{tabular}{|c|c|c|c|c|c|}
\hline \multirow{5}{*}{$\begin{array}{l}\text { Second Family: } \\
\text { Methoxybenzene- } \\
\text { based coumarins } \\
\text { and } \\
\text { Ethoxycoumarins }\end{array}$} & M2 & n.p. & 61 & n.p. & 77 \\
\hline & M3 & n.p. & 63 & n.p. & 77 \\
\hline & M4 & 37 & 73 & 66 & 84 \\
\hline & M5 & n.p. & 59 & n.p. & 77 \\
\hline & M6 & n.p. & 42 & n.p. & 76 \\
\hline \multirow{6}{*}{$\begin{array}{c}\text { Third Family: } \\
\text { Thiophene-based } \\
\text { coumarins }\end{array}$} & $\mathrm{T} 1$ & n.p. & 55 & n.p. & 77 \\
\hline & $\mathrm{T} 2$ & n.p. & 60 & n.p. & 78 \\
\hline & T3 & 14 & 62 & n.p. & 79 \\
\hline & T4 & n.p. & 61 & n.p. & 77 \\
\hline & T5 & n.p. & 61 & n.p. & 77 \\
\hline & T6 & n.p. & 64 & 49 & 81 \\
\hline $\begin{array}{l}\text { Fourth Family: } \\
\text { Alkyne-based } \\
\text { coumarin }\end{array}$ & A1 & n.p. & 58 & n.p. & 73 \\
\hline
\end{tabular}

n.p.: no polymerization

\subsection{Comparison between families}

\subsubsection{Free radical photopolymerization of acrylates}

Different families of coumarins were designed for the FRP of TMPTA in thin $(25 \mu \mathrm{m}$, in laminate) and thick (1.4 mm, under air) samples upon irradiation with the LED @405 nm. After comparison of the performance of the different coumarins in each family, the best ones of each family will be now compared together for thin films (N1, N2, M3, M4, T3, T6, A1) (Figure 10). 
In this series, $\mathbf{N} 2$ has been chosen as the best PI with Iod but also as a type II combined with NPG or EDB. Whereas, $\mathbf{N 1}$ has the highest performance in the presence of three-component systems.

(A)

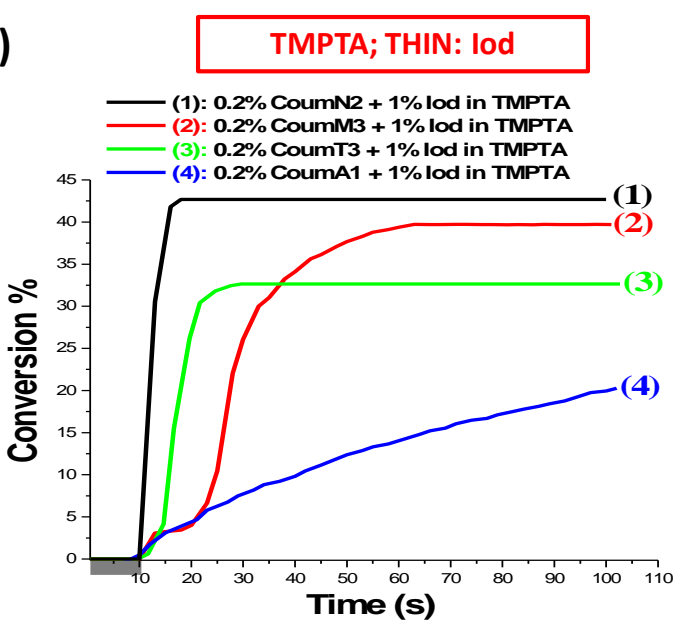

(C)

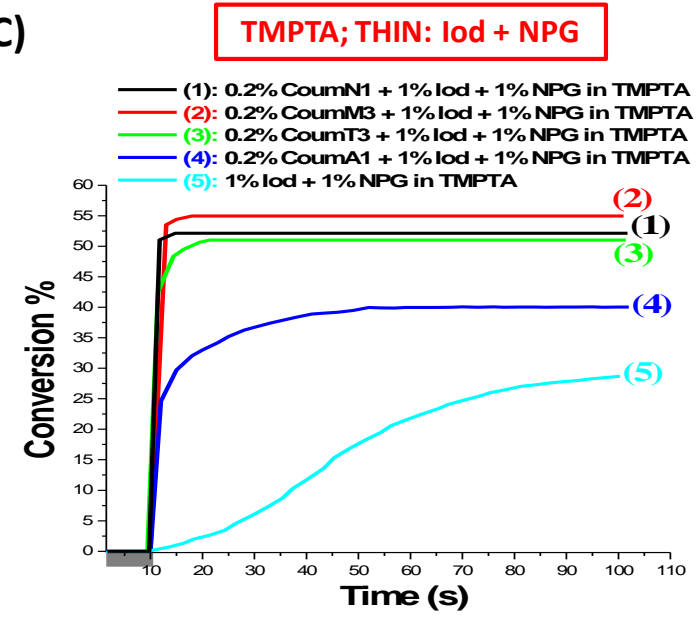

(B)

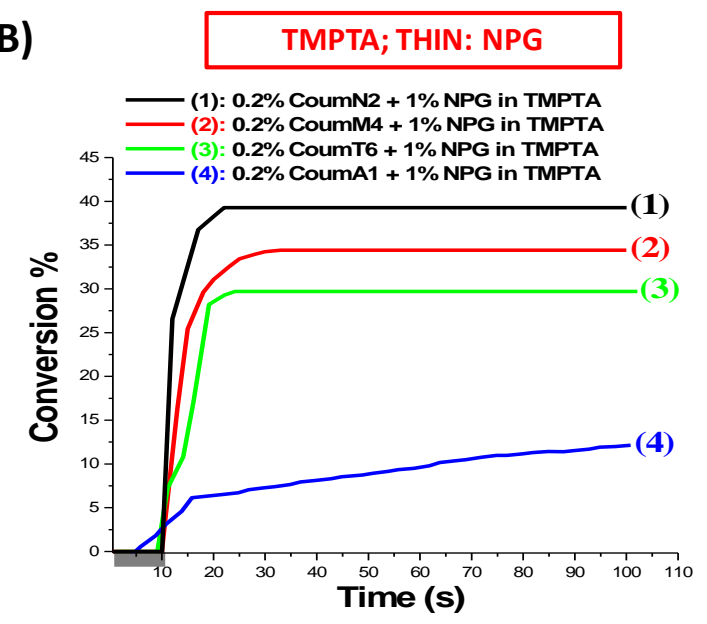

(D)

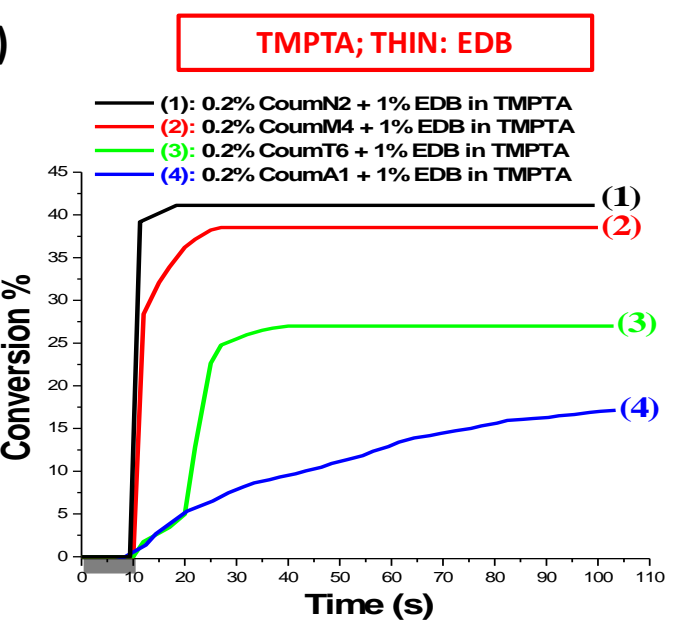

Figure 10. Polymerization profiles (acrylate function conversion vs. irradiation time) of thin (25 $\mu \mathrm{m})$ TMPTA films, in laminate upon irradiation with the LED@ $405 \mathrm{~nm}$ in the presence of different two and three-component photoinitiating systems involving the best coumarins of each family: (A): PI/Iod (0.2\%/1\% w/w): (1) N2/Iod; (2) M3/Iod; (3) T3/Iod; and (4) A1/Iod. (B): PI/NPG (0.2\%/1\% w/w): (1) N2/NPG; (2: M4/NPG; (3) T6/NPG; and (4) A1/NPG. (C): PI/Iod/NPG (0.2\%/1\%/1\% w/w): (1) N1/Iod/NPG; (2) M3/Iod/NPG; (3) T3/Iod/NPG; and (4) A1/Iod/NPG. (D): PI/EDB (0.2\%/1\% w/w): (1) N2/EDB; (2) M4/EDB; (3) T6/EDB; and (4) A1/EDB. The irradiation is launched for $\mathrm{t}=10 \mathrm{~s}$.

Secondly, the best candidates of each family are compared together for thick films (N2, M3,

M4, T1, T6, A1) (Figure 11). In this series, N2 was the best photoinitiator with Iod but also the 
best type II photoinitiator when associated with EDB among the four studied families. When combined with NPG, M4 has been picked as the best PI for a photo-reduction process. For the three-component systems, N1, N2, N3 and M4 are able to initiate the FRP of TMPTA thick samples in the same way (Figure 5C and Figure 11C).

(A)

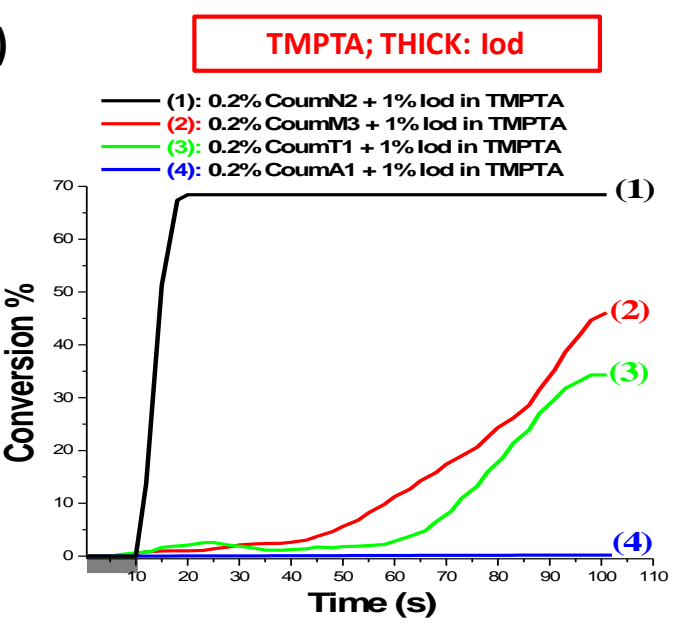

(C)

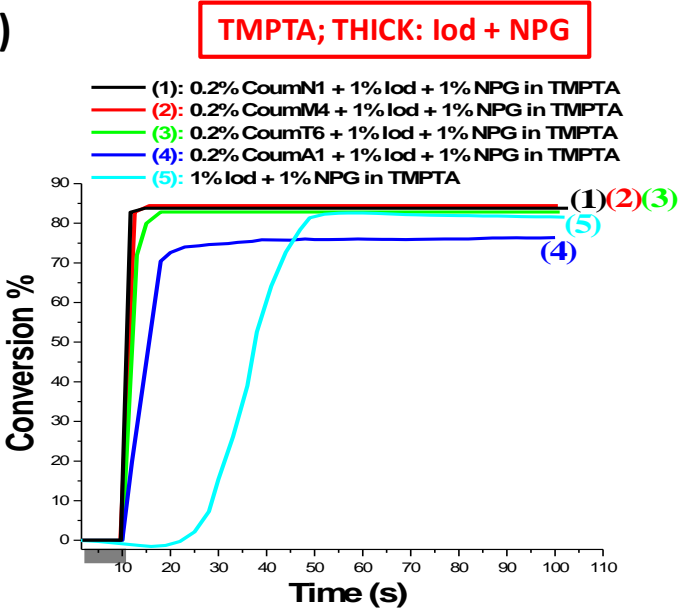

(B)

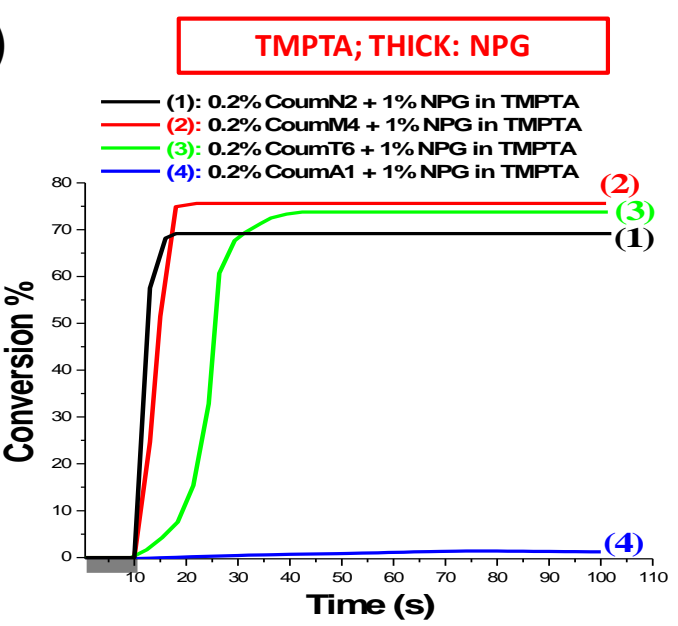

(D)

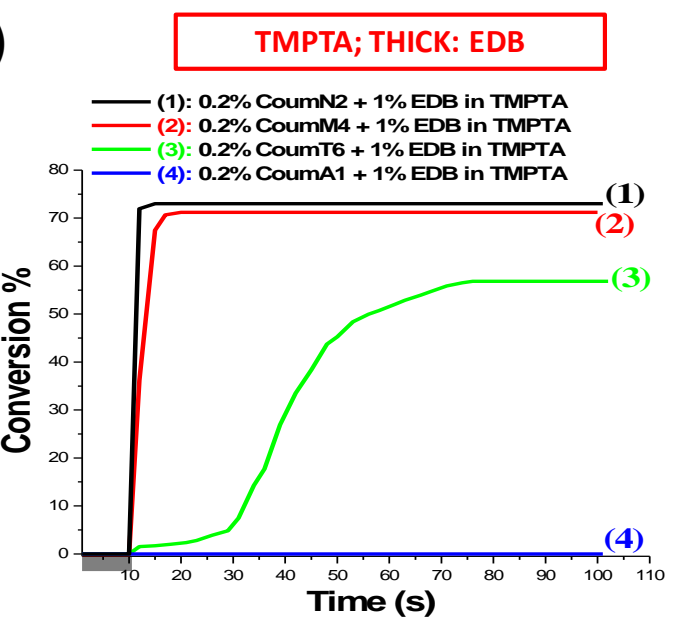

Figure 11. Polymerization profiles (acrylate function conversion vs. irradiation time) of $1.4 \mathrm{~mm}$ thick samples of TMPTA (under air, using LED@405 nm) in the presence of different two and three-component photoinitiating systems involving the best coumarins of each family: (A): PI/Iod (0.2\%/1\% w/w): (1) N2/Iod; (2) M3/Iod; (3) T1/Iod; and (4) A1/Iod. (B): PI/NPG (0.2\%/1\% w/w): (1) N2/NPG; (2) M4/NPG; (3) T6/NPG; and (4) A1/NPG. (C): PI/Iod/NPG (0.2\%/1\%/1\% w/w): (1) N1/Iod/NPG; (2) M4/Iod/NPG; (3) T6/Iod/NPG; and (4) A1/Iod/NPG. (D): PI/EDB (0.2\%/1\% w/w): (1) N2/EDB; (2) M4/EDB; (3) T6/EDB; and (4) A1/EDB. The irradiation is launched for $\mathrm{t}=10 \mathrm{~s}$. 


\subsubsection{Free radical photopolymerization of methacrylates (BisGMA/TEGDMA)}

Again, the most efficient coumarins of each family were selected for comparison purposes in methacrylates: N1 and N2 for Nitrocoumarins, M4 for Methoxybenzene-based coumarins and Ethoxycoumarins family, $\mathbf{T 3}$ and $\mathbf{T 6}$ for Thiophene-based structures and A1 for the Alkyne-based coumarin (Figure 12). It is clearly found that $\mathbf{N 1}$ can be chosen as the best structure in combination with the Iodonium salt. Whereas, $\mathbf{N} \mathbf{2}$ was found the best one among the four studied families in combination with amine (Type II photoinitiator) but also in the presence of three-component systems. 
(A)
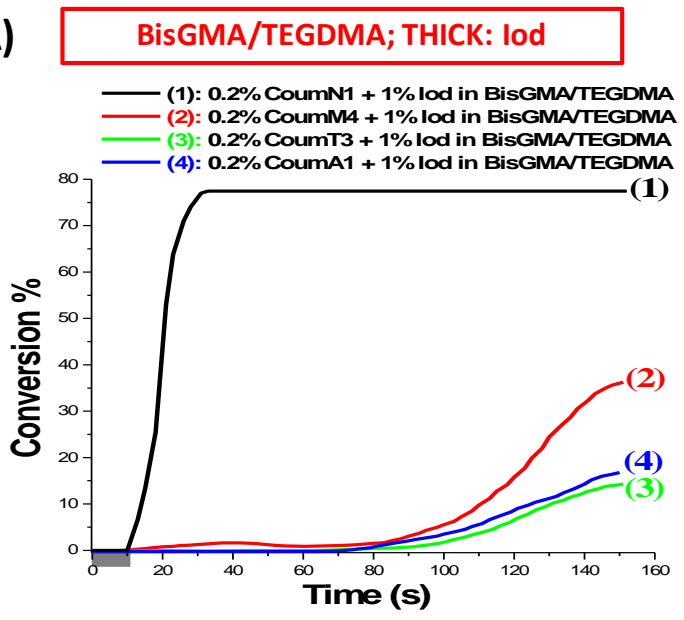

(C)

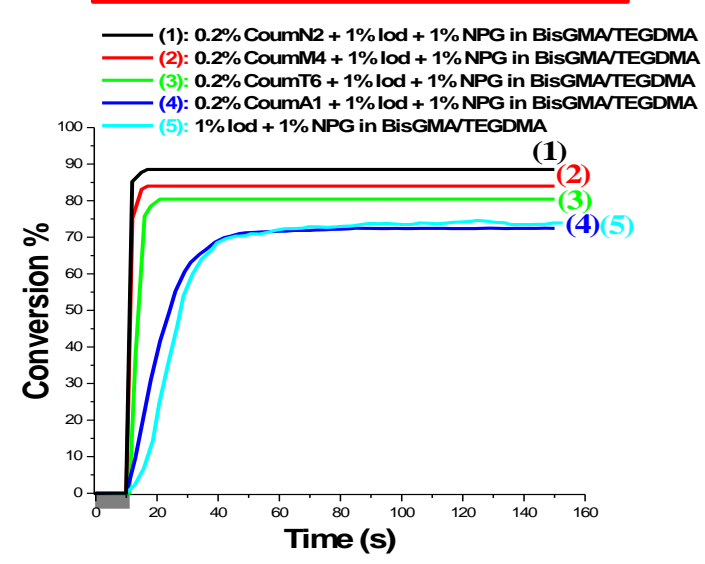

(B)

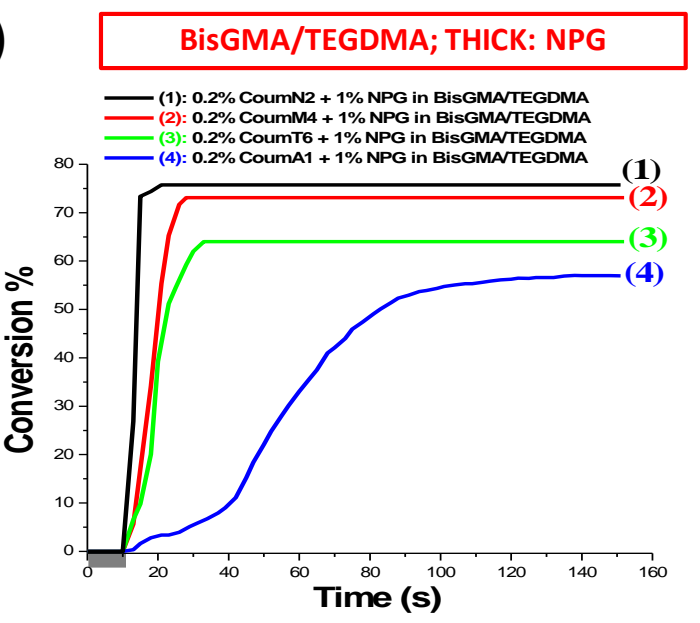

(D) BisGMA/TEGDMA; THICK: EDB

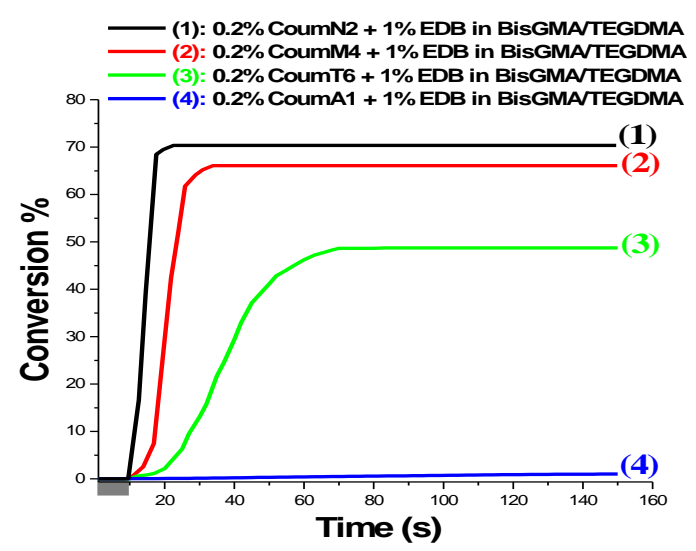

Figure 12. Polymerization profiles (methacrylate function conversion vs. irradiation time) of 1.4 mm thick samples of BisGMA/TEGDMA blend (under air, using LED@405 nm) in the presence of different two and three-component photoinitiating systems involving the best coumarins: (A): PI/Iod (0.2\%/1\% w/w): (1) N1/Iod; (2) M4/Iod; (3) T3/Iod; and (4) A1/Iod. (B): PI/NPG (0.2\%/1\% w/w): (1) N2/NPG; (2) M4/NPG; (3) T6/NPG; and (4): A1/NPG. (C): PI/Iod/NPG (0.2\%/1\%/1\% w/w): (1) N2/Iod/NPG; (2) M4/Iod/NPG; (3) T6/Iod/NPG; and (4) A1/Iod/NPG. (D): PI/EDB (0.2\%/1\% w/w): (1) N2/EDB; (2) M4/EDB; (3) T6/EDB; and (4) A1/EDB. The irradiation is launched for $\mathrm{t}=10 \mathrm{~s}$.

\subsection{Coumarin/NPG \& Coumarin/Iod/NPG Systems in 3D Printing Experiments}

3D printing experiments were successfully carried out under air by means of a laser diode @ $405 \mathrm{~nm}$ and in the presence of different two (Coum/NPG) or three-component (Coum/Iod/NPG) systems based on TMPTA or BisGMA/TEGDMA as the resins (Figure 13 and Figure S10). 
Actually, the high photosensitivity of the proposed systems allows an efficient polymerization process in the irradiated area in 3D printing experiments. The obtained 3D patterns are characterized by means of a numerical optical microscopy (Figure 13 and Figure S10). Remarkably, the preparation of very thick 3D polymer samples can be obtained in a very short irradiation time $(\sim 1 \mathrm{~min})$ and with a high spatial resolution (only limited by the size of the laser diode beam: spot of $50 \mu \mathrm{m})$.

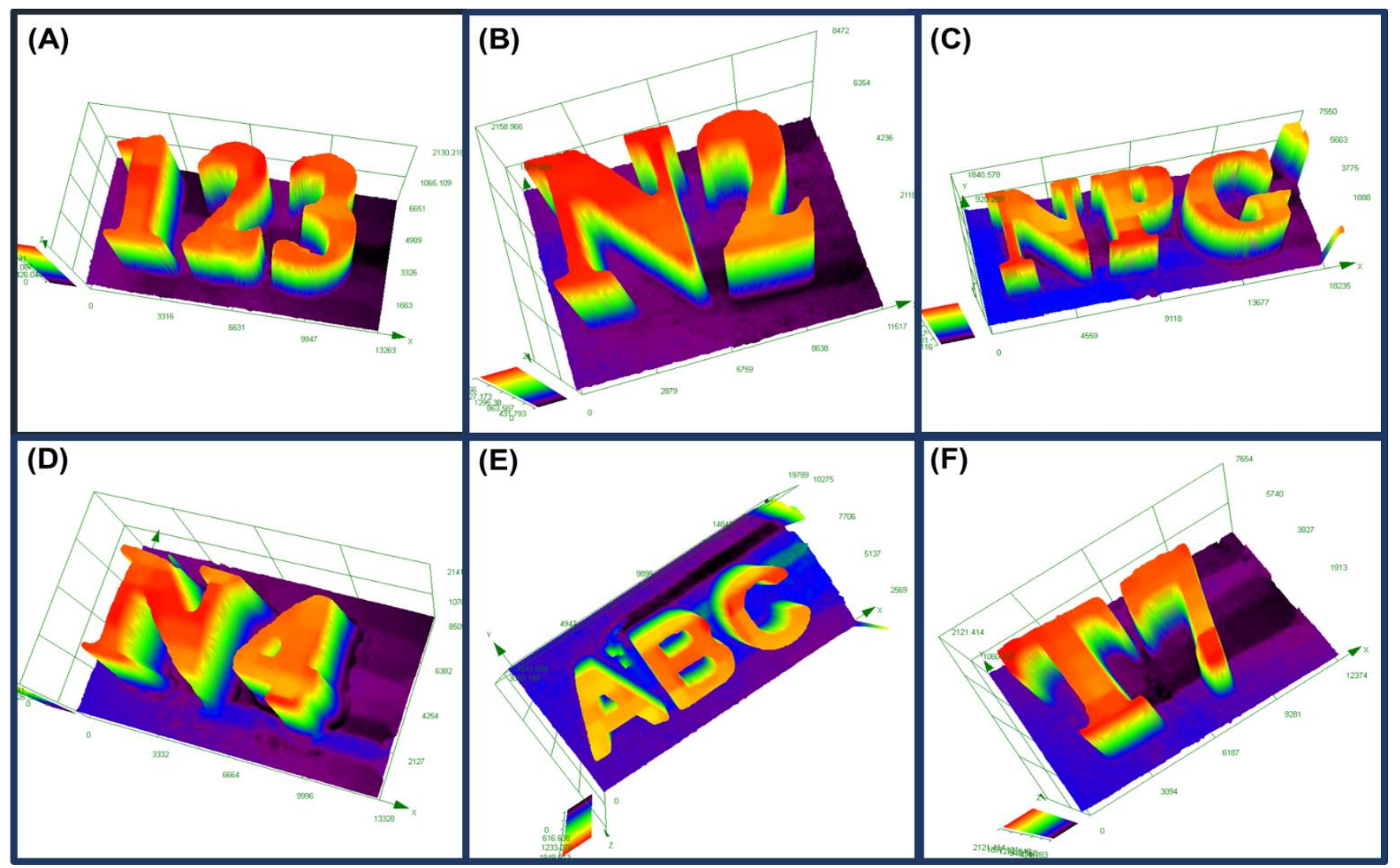

Figure 13. 3D-printing experiments using a laser diode @ $405 \mathrm{~nm}$ : Characterization of the 3D written patterns by a numerical optical microscopy; (A): T7/NPG $(0.067 \% / 0.333 \% \mathrm{w} / \mathrm{w})$ in TMPTA (thickness $=2130 \mu \mathrm{m}) ;(\mathbf{B}): \mathbf{N 2} / \mathrm{Iod} / \mathrm{NPG}(0.062 \% / 0.24 \% / 0.24 \% \mathrm{w} / \mathrm{w})$ in TMPTA (thickness $=2160 \mu \mathrm{m}) ;(\mathbf{C}): \mathbf{N} 4 / \mathrm{Iod} / \mathrm{NPG}(0.05 \% / 0.25 \% / 0.25 \% \mathrm{w} / \mathrm{w})$ in TMPTA (thickness = $1840 \mu \mathrm{m})$; (D): N4/EDB $(0.067 \% / 0.333 \% \mathrm{w} / \mathrm{w})$ in TMPTA (thickness $=2140 \mu \mathrm{m}) ;(\mathbf{E})$ : N6/Iod/NPG $(0.05 \% / 0.25 \% / 0.25 \% \mathrm{w} / \mathrm{w})$ in TMPTA (thickness $=3083 \mu \mathrm{m})$; and (F): T7/Iod/NPG $(0.068 \% / 0.339 \% / 0.339 \% \mathrm{w} / \mathrm{w})$ in TMPTA (thickness $=2120 \mu \mathrm{m})$; respectively.

\subsection{Near-UV conveyor experiments for the access to photocomposites}


Due to the astonishing polymerization initiating abilities of some coumarins investigated above, their use for the preparation of photocomposites has been checked. Indeed, composite materials have several huge advantages: high strength, lightweight, corrosion and chemical resistance that lead to reinforced materials heavily required for industrial applications. However, the light penetration issue in such materials required the development of highly efficient photoinitiating systems that can work even for low light intensity in depth.

Currently, the preparation of the photocomposites involves the preparation of prepregs by impregnation of glass fibers with an organic resin (50\% glass fibers/50\% resin based on TMPTA or BisGMA/TEGDMA blend $(70 \% / 30 \% \mathrm{w} / \mathrm{w}))$ and then the irradiation of the sample with the LED at $395 \mathrm{~nm}$. With regards to the experimental results, the proposed coumarins were able to perfectly cure composites, highlighting again their excellent reactivity. This behavior is proven by a very fast curing polymerization where a very small number of passes is required to get tack-free photocomposites e.g. the surface became tack-free after only one pass of irradiation with the LED@ $395 \mathrm{~nm}$ (for $2 \mathrm{~m} / \mathrm{min}$ belt speed), and within one or few passes for the bottom of the sample (Figure 14 \& Figure S11 with BisGMA/TEGDMA resin and Figure S12 with TMPTA resin), using one layer of glass fibers (thickness $=2 \mathrm{~mm}$ ). The results are gathered in Tables S1 \& S2 in SI. An excellent depth of cure upon irradiation with the LED @ $395 \mathrm{~nm}$ can be observed for these systems. Moreover, for the proposed coumarins, colorless or light colored composites were generated. 


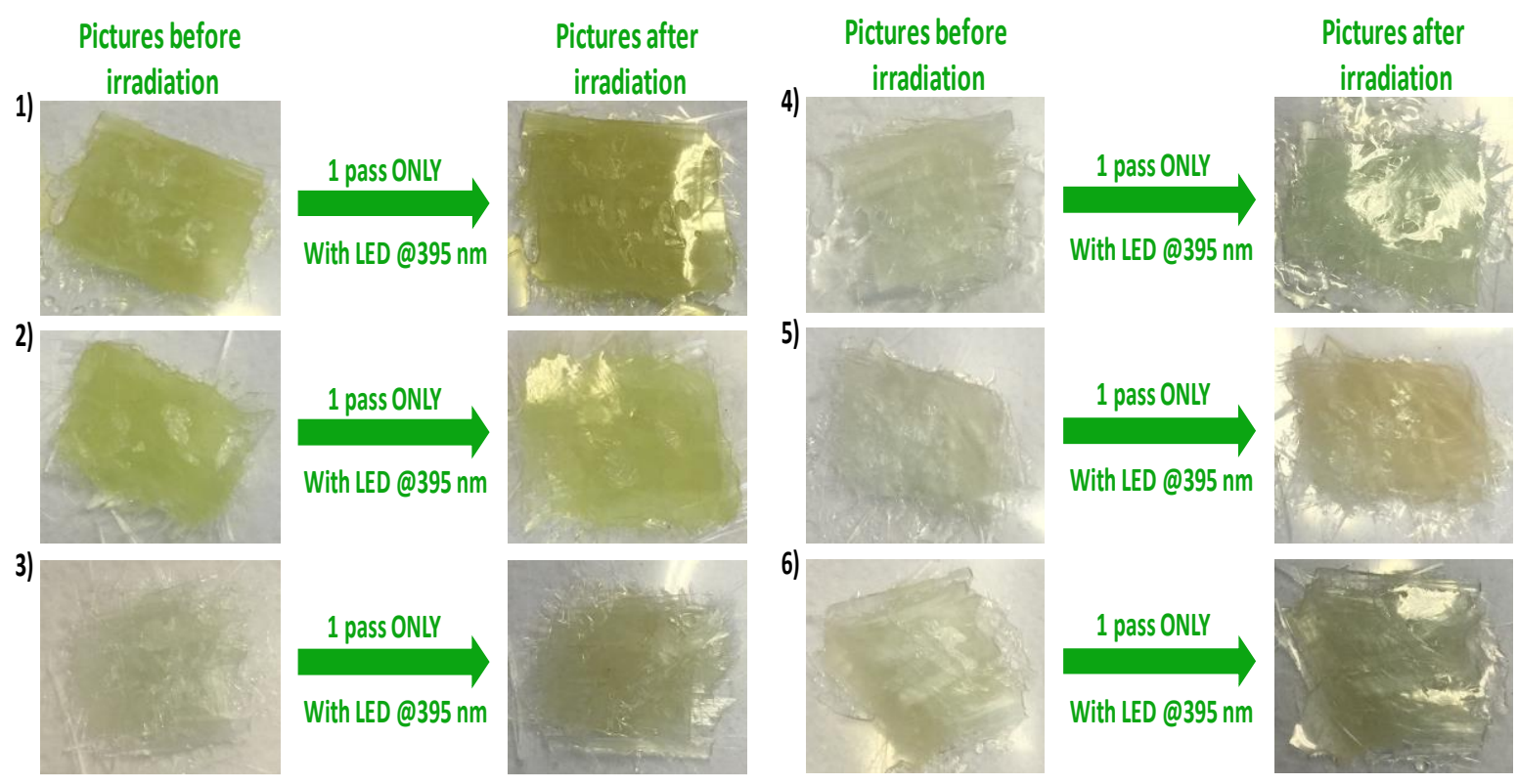

Figure 14. Photocomposites produced upon Near-UV light (LED @ 395 nm) exposure, Belt Speed $=2 \mathrm{~m} / \mathrm{min}$, using the free radical polymerization (FRP) in the presence of $50 \%$ glass fibers $/ 50 \%$ methacrylate resin (thickness $=2 \mathrm{~mm}$ for one layer of glass fibers) for different systems. First Family: Nitrocoumarins: (1) $0.2 \%$ N1 + $1 \%$ Iod + $1 \%$ NPG; (2) $0.2 \%$ N1 + $1 \%$ Iod; (3) $0.2 \%$ N2 $+1 \%$ Iod + $1 \%$ NPG; (4) $0.2 \%$ N2 + 1\% NPG; (5) $0.2 \%$ N6 + $1 \%$ Iod + $1 \%$ NPG; (6): $0.2 \%$ N6 $+1 \%$ NPG.

\subsection{Chemical Mechanisms}

\subsubsection{Steady State Photolysis}

Using UV-Visible spectroscopy, photolysis experiments for the different initiating systems were carried out. M3 is selected here as a representative compound. Currently, a very fast photolysis is observed for M3/Iod in acetonitrile compared to that of M3 alone (Figure 15B vs. Figure 15A using the LED@375 nm), indicating a strong interaction between M3 and Iod. Furthermore, it should be noted that the high reactivity and efficiency of this system in polymerization is in line with the strong bleaching observed during the photolysis experiment. Interestingly, an isobestic point appears at about $310 \mathrm{~nm}$, which confirms that no other secondary reaction has taken place. The consumption of $\mathbf{M 3}$ is clearly illustrated in Figure $15 \mathrm{C}$, where the 
optical density of the solution is measured at different irradiation time in the presence of Iod (Figure 15C, curve 2) and without addition of Iod (Figure 15C, curve 1).

(A)

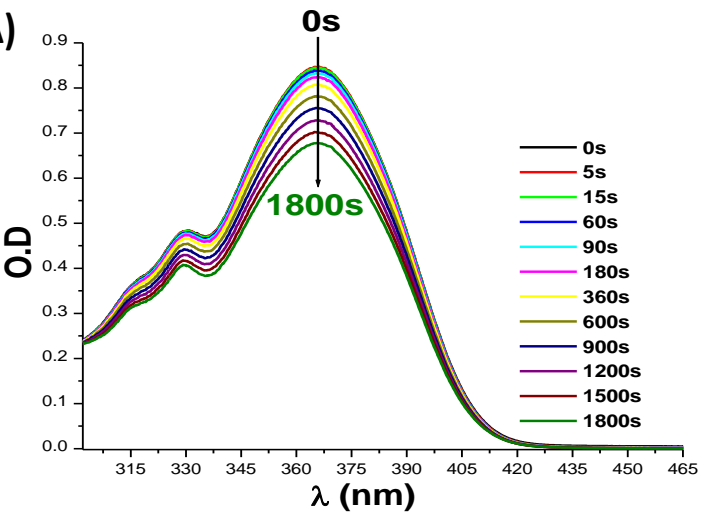

(B)

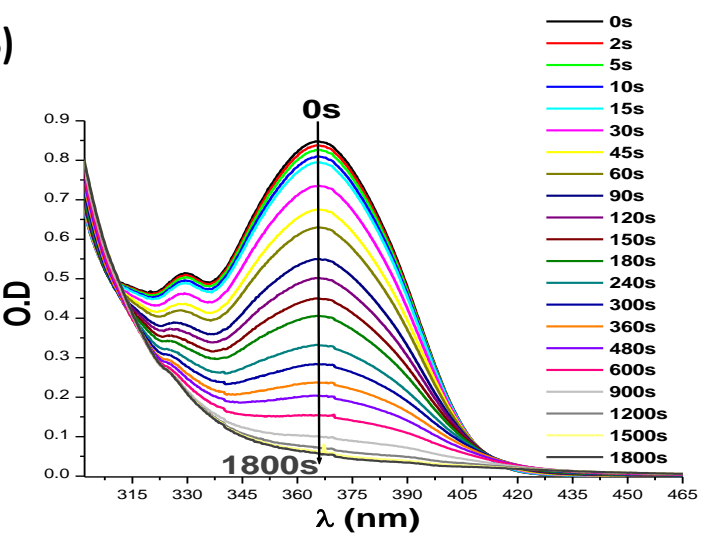

(C)

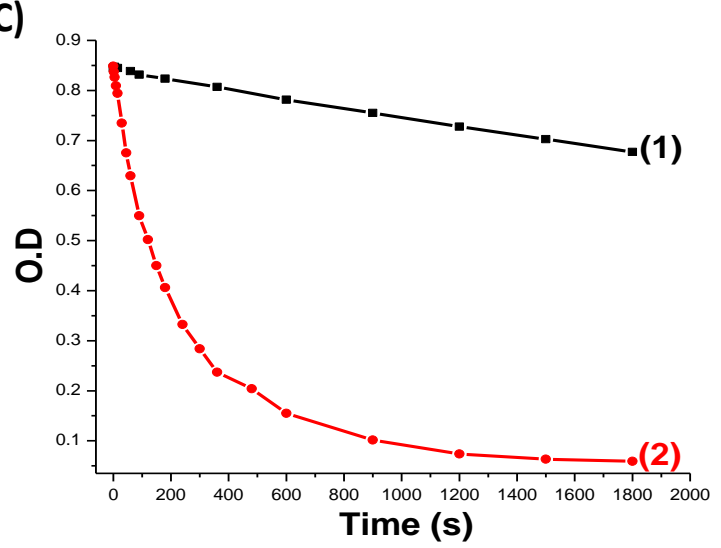

Figure 15. (A): Photolysis of M3 alone (in absence of Iod); (B): Photolysis of M3/Iod; and (C): Photodegradation of M3 at $365 \mathrm{~nm}$ without (1) and with (2) Iod salt vs. irradiation time, using the LED @375 nm in ACN.

\subsubsection{Fluorescence quenching, Cyclic Voltammetry and ESR Experiments}

Fluorescence and fluorescence quenching experiments for the different coumarins involved in this work were carried out for a better understanding of their excited state reactivity (a representative compound (M3) is selected; see Figure S13). First, the energy of the singlet excited 
state $\left(E_{S 1}\right)$ can be determined by the crossing point between the absorption and the fluorescence spectra e.g. $\mathrm{E}_{\mathrm{S} 1}=3.08 \mathrm{~V}$ for $\mathbf{M 3}$ (Figure S13A; Table 5). The redox potential of coumarin derivatives were determined by cyclic voltammetry (Table 5) allowing the evaluation of the free energy change for the electron transfer reaction. For N2 and T2, slightly higher oxidation potentials than for the other coumarins were found but the electron transfer remains favorable (Table 5).

Table 5. Parameters Characterizing the Photochemical Mechanisms Associated with ${ }^{1,3} \mathrm{Coum} / \mathrm{Iod}$ in Acetonitrile.

\begin{tabular}{|c|c|c|c|c|c|c|c|c|}
\hline Family & PI & $\begin{array}{l}E_{S 1} \\
(e V)\end{array}$ & $\begin{array}{c}\mathrm{E}_{\mathrm{T} 1} \\
(\mathrm{eV})^{\mathrm{a}}\end{array}$ & $\begin{array}{l}E_{o x} \\
(e V)\end{array}$ & $\begin{array}{c}\Delta \mathrm{G}_{\mathrm{et}(\mathrm{S} 1)^{\mathrm{b}}} \\
\text { (Coumarin/lod) } \\
(\mathrm{eV})\end{array}$ & $\begin{array}{c}\Delta \mathrm{G}_{\mathrm{et}(\mathrm{T} 1)^{\mathrm{c}}} \\
\text { (Coumarin/lod) } \\
(\mathrm{eV})\end{array}$ & $\begin{array}{c}\mathrm{K}_{\mathrm{sV}} \\
\text { (Coumarin/lod) } \\
\left(\mathrm{M}^{-1}\right)\end{array}$ & $\begin{array}{c}\phi_{\text {et(S1) }} \\
{ }^{d} \text { (Coumarin/lod) }\end{array}$ \\
\hline \multirow{6}{*}{$\begin{array}{l}\text { First Family: } \\
\text { Nitrocoumarins }\end{array}$} & N1 & 2.88 & 2.01 & 0.53 & -2.15 & -1.28 & 35.05 & 0.39 \\
\hline & N2 & - & 2.24 & 1.16 & - & -0.88 & - & - \\
\hline & N3 & 3.26 & 2.18 & 0.72 & -2.34 & -1.26 & 49.35 & 0.48 \\
\hline & N4 & - & 2.21 & 0.66 & - & -1.35 & - & - \\
\hline & N5 & 3.31 & 2.21 & 0.71 & -2.4 & -1.3 & 59.34 & 0.52 \\
\hline & N6 & 3.47 & 2.17 & 0.77 & -2.5 & -1.2 & 14.24 & 0.21 \\
\hline \multirow{4}{*}{$\begin{array}{l}\text { Second Family: } \\
\text { Methoxybenzene- } \\
\text { based coumarins }\end{array}$} & M1 & 3.28 & 2.16 & 0.75 & -2.33 & -1.21 & 26.05 & 0.33 \\
\hline & M2 & 3.28 & 2.12 & 0.6 & -2.48 & -1.32 & 86.65 & 0.62 \\
\hline & M3 & 3.08 & 1.96 & 0.55 & -2.33 & -1.21 & 40.66 & 0.43 \\
\hline & M4 & 3.32 & 2.07 & 0.77 & -2.35 & -1.1 & 16.74 & 0.24 \\
\hline
\end{tabular}




\begin{tabular}{|c|c|c|c|c|c|c|c|c|}
\hline & M5 & 3.26 & 2.11 & 0.63 & -2.43 & -1.28 & 79.16 & 0.6 \\
\hline & M6 & 3.3 & 2.23 & 0.74 & -2.36 & -1.29 & 147.76 & 0.73 \\
\hline \multirow{6}{*}{$\begin{array}{c}\text { Third Family: } \\
\text { Thiophene-based } \\
\text { coumarins }\end{array}$} & $\mathrm{T} 1$ & 3.16 & 1.88 & 0.63 & -2.33 & -1.05 & 30.96 & 0.37 \\
\hline & $\mathrm{T} 2$ & 2.69 & 1.85 & 1.12 & -1.37 & -0.49 & 135.59 & 0.72 \\
\hline & T3 & 3.15 & 1.73 & 0.65 & -2.3 & -1 & 48.1 & 0.47 \\
\hline & T4 & 2.95 & 1.85 & 0.65 & -2.1 & -0.88 & 47.2 & 0.47 \\
\hline & T5 & 3.18 & 1.85 & 0.6 & -2.38 & -1.05 & 76.8 & 0.59 \\
\hline & T6 & 3.16 & 1.81 & 0.64 & -2.32 & -1.01 & 49.45 & 0.48 \\
\hline $\begin{array}{l}\text { Fourth Family: } \\
\text { Alkyne-based } \\
\text { coumarin }\end{array}$ & A1 & 2.74 & 2.06 & 1.04 & -1.5 & -0.82 & 14.24 & 0.21 \\
\hline
\end{tabular}

${ }^{\text {a }}$ calculated triplet state energy level at DFT level. UB3LYP/6-31G* level of theory.

${ }^{\mathrm{b}} \Delta \mathrm{G}_{\mathrm{et}}$ from $\mathrm{S}_{1}$ calculated according to eq.1, and a reduction potential of $-0.2 \mathrm{eV}$ was used for Iod [21].

${ }^{c} \Delta \mathrm{G}_{\text {et }}$ from $\mathrm{T}_{1}$ calculated according to eq. 1 , and a reduction potential of $-0.2 \mathrm{eV}$ was used for Iod [21].

${ }^{\mathrm{c}} \phi_{\text {et }}$ calculated according to eq. $2[21]$.

In fact, the ${ }^{1}$ Coum/Iod fluorescence quenching processes are highly favorable as shown from i) the high values of the Stern-Volmer coefficients (Ksv; Table 5), ii) the good electron transfer quantum yields ( $\phi_{\mathrm{et}}$; calculated applying eq. 2 ; Table 5) and iii) advantageous free energy changes $\left(\Delta \mathrm{G}_{\mathrm{et}}\right)$ for the electron transfer reaction between coumarins as electron donors and Iodonium salt as electron acceptor ( $\mathrm{r} 1 \& \mathrm{r} 2$ in Scheme 4). 


\section{$\phi_{\text {et }}=K_{\mathrm{sv}}[\operatorname{Iod}] /\left(\mathbf{1}+K_{\mathrm{sv}}[\operatorname{Iod}]\right) \quad($ eq. 2$)$}

We note that a triplet state pathway cannot be ruled out, while the singlet state pathway probably dominates thanks to the more favorable free energy changes from $\mathrm{S} 1\left(\Delta \mathrm{G}_{\mathrm{et}(\mathrm{S} 1)}\right)$ compared to those calculated from $\mathrm{T} 1\left(\Delta \mathrm{G}_{\mathrm{et}(\mathrm{T} 1)}\right)$.

To clarify the interactions that happened, a global mechanism is provided and illustrated in the Scheme 4 (reactions r1-r8) according to other dyes used as PIs [17,28]. It is suggested that the Coumarin/Iod interaction takes place through the classical [48] reduction of the iodonium salt (r1 and r2) (see above, the favorable $\Delta \mathrm{G}_{\text {et }}$ and the fluorescence quenching data). This latter proposed mechanism is completely confirmed by Electron Spin Resonance (ESR) technique which provides the detection of aryl radicals. Indeed, the irradiation of the Coum/Iod solution in the presence of the spin-trap agent (phenyl-N-tert-butylnitrone (PBN)) allows the detection of the generated aryl radicals $\left(\mathrm{Ar}^{\bullet}\right)$ (in agreement with $\mathrm{r} 2$ ) in the form of $\left(\mathrm{Ar}^{\bullet}\right) / \mathrm{PBN}$ radical adducts, which are characterized by typical hyperfine coupling constants (hfes): $\mathrm{a}_{\mathrm{N}}=14.3 \mathrm{G}$ and $\mathrm{a}_{\mathrm{H}}=2.2 \mathrm{G}$ in full agreement with reported data [49]. Note that aryl radicals are considered as excellent initiating species for addition onto (meth)acrylate double bond $\left(\mathrm{k}_{\mathrm{add}}=10^{8} \mathrm{M}^{-1} \cdot \mathrm{s}^{-1}\right)$ [21] suitable with the great efficiencies of the Coum/Iod systems in photopolymerization reactions.

Besides, it is suggested that a Charge Transfer Complex (CTC) can be formed between NPG which is an $\mathrm{N}$-aromatic electron donor and iodonium salt which is an electron poor (r3) like what has been very recently published [50]. An example of similar [NPG-Iod] $]_{\text {CTC }}$ structure is available in the literature [50]. An enhanced visible light absorption is provided to the photoinitiating system in the presence of the quite convenient [NPG-Iod $]_{\text {CTC }}$ structure. In addition, the photolysis of this latter structure at $405 \mathrm{~nm}$ leads to an efficient release of aryl radicals $\left(\mathrm{Ar}^{\bullet}\right)(\mathrm{r} 4)$ as affirmed by the 
photopolymerization study (curve (7) in Figures 4C, 5C, 6B, 6D, 7B, 7D, 8C, 9B \& 9D and curve (5) in Figures S5A, S5B \& S5C).

Moreover, taking into consideration the Coum/NPG interaction, an electron/proton transfer reaction can be proposed ( $\mathrm{r} 1$ and $\mathrm{r} 5$ ) which ends with the formation of $\mathrm{NPG}_{(-\mathrm{H})}{ }^{\bullet}$. In order to avoid any back electron transfer reaction, a decarboxylation reaction (r6) leading to the formation of

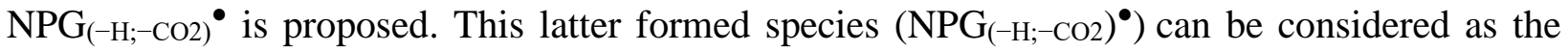
initiating species for the free radical polymerization that occurs in the presence of Coum/NPG systems.

With regards to the three-component systems, $r 7$ and $r 8$ are proposed, based on other dye/iodonium salt/amine combinations previously studied in the literature [50]. Consequently, $\mathrm{Ar}^{\bullet}, \mathrm{NPG}_{(-\mathrm{H} ;-\mathrm{CO} 2)^{\bullet}}$, and Coumarin ${ }^{\bullet+}, \mathrm{NPG}_{(-\mathrm{H} ;-\mathrm{CO} 2)}{ }^{+}$can be envisioned as the initiating species for FRP and CP, respectively.

Coumarin $\rightarrow{ }^{*}$ Coumarin $\quad(h v)$

${ }^{*}$ Coumarin $+\mathrm{Ar}_{2} \mathrm{I}^{+} \rightarrow$ Coumarin $^{\bullet+}+\mathrm{Ar}_{2} \mathrm{I}^{\bullet} \rightarrow$ Coumarin $^{\bullet+}+\mathrm{Ar}^{\bullet}+\mathrm{ArI}$

$\mathrm{NPG}+\mathrm{Iod} \rightarrow[\mathrm{NPG}-\mathrm{Iod}]_{\mathrm{CTC}}$

$[\mathrm{NPG}-\mathrm{Iod}]_{\mathrm{CTC}} \rightarrow \rightarrow \rightarrow \mathrm{Ar}^{\bullet}$

${ }^{*}$ Coumarin $+\mathrm{NPG} \rightarrow(\text { Coumarin-H })^{\bullet}+\mathrm{NPG}_{(-\mathrm{H})}{ }^{\bullet}$

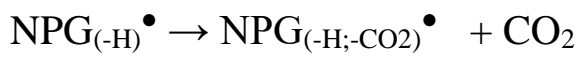

$\mathrm{NPG}_{(-\mathrm{H} ;-\mathrm{CO} 2)}+\mathrm{Ar}_{2} \mathrm{I}^{+} \rightarrow \mathrm{NPG}_{(-\mathrm{H} ;-\mathrm{CO} 2)}{ }^{+}+\mathrm{Ar}^{\bullet}+\mathrm{ArI}$

$(\text { Coumarin-H })^{\bullet}+\mathrm{Ar}_{2} \mathrm{I}^{+} \rightarrow$ Coumarin $+\mathrm{H}^{+}+\mathrm{Ar}^{\bullet}+\mathrm{ArI}$

Scheme 4. Proposed Photochemical Mechanisms.

\section{Conclusion}


In the present paper, using in-silico development by molecular modeling, four families of coumarins were synthesized and examined as photoinitiators for both the cationic polymerization of epoxides and the free radical polymerization of (meth)acrylates under near-violet or blue LEDs. High photoinitiating abilities were attained with these compounds, particularly with Nitrocoumarins. A set of parameters made these compounds very efficient photoinitiators, among which a highly favorable free energy changes $\left(\Delta \mathrm{G}_{\mathrm{et}}\right)$ for electron transfer reaction, strong absorption properties and appropriate oxidation potentials at the excited state can be cited as the most relevant ones. The outstanding reactivity of the coumarins investigated in this study is also demonstrated by mean of 3D printing experiments done with a laser diode @ $405 \mathrm{~nm}$. These efficient coumarin derivatives were also successfully used for the preparation of photocomposites possessing an excellent depth of cure under the LED @395 nm. The developments of new high performance photoinitiating systems based on other coumarins suitable for 3D printing applications and also for the curing of carbon fibers prepregs will be presented in forthcoming papers.

\section{Acknowledgments:}

The Lebanese group would like to thank "The Association of Specialization and Scientific Guidance" (Beirut, Lebanon) for funding and supporting this scientific work. This work was granted access to the HPC resources of the Mesocentre of the University of Strasbourg and by the Region Grand-Est for the project MIPPI-4D.

Supporting Information: Figure S1: Contour plots of HOMOs and LUMOs for the other tested coumarin derivatives; structures optimized at the B3LYP/6-31G* level of theory; Figure S2: Color before and after photopolymerization for the "First Family: Nitrocoumarins" in TMPTA; 
Figure S3: Color before and after photopolymerization for the "Second Family: Methoxybenzene-based coumarins and Ethoxycoumarins" in TMPTA; Figure S4: Color before and after photopolymerization for the "Third Family: Thiophene-based coumarins" in TMPTA; Figure S5: Typical (meth)acrylate function conversion-time profiles for thin $(25 \mu \mathrm{m}$, in laminate) and thick (1.4 mm, under air) TMPTA (or BisGMA/TEGDMA) samples in the presence of the "Fourth Family: Alkyne-based coumarin" upon exposure to the LED at $405 \mathrm{~nm}$; Figure S6: Color before and after photopolymerization for the "Fourth Family: Alkyne-based coumarin" in (meth)acrylate; Figure S7: Color before and after photopolymerization for the "First Family: Nitrocoumarins"' in BisGMA/TEGDMA; Figure S8: Color before and after photopolymerization for the "Second Family: Methoxybenzene-based coumarins and Ethoxycoumarins" in BisGMA/TEGDMA; Figure S9: Color before and after photopolymerization for the "Third Family: Thiophene-based coumarins" in BisGMA/TEGDMA; Figure S10: Characterization of the other 3D written patterns by a numerical optical microscopy. Figure S11 and Figure S12: Synthesis of photocomposites (thickness $=2 \mathrm{~mm}$ ) using (meth)acrylate resins upon Near-UV light (LED @ $395 \mathrm{~nm}$ ); Table S1 and Table S2: Number of passes to be tack-free for impregnated glass fibers with (meth)acrylate resins using a Near-UV conveyor (LED @395 nm), belt speed used = 2 m. $\mathrm{min}^{-1}$; and Figure S13: Fluorescence quenching of $\mathbf{M 3}$ and Stern-Volmer treatment. 


\section{REFERENCES:}

[1] Yourick, J. J.; Bronaugh, R. L. Percutaneous Absorption and Metabolism of Coumarin in Human and Rat Skin. J. Appl. Toxicol. 1997, 17, 153-158.

[2] O’Kennedy R.; Thornes R. D. Coumarins: Biology, Applications, and Mode of Action; Suggested Modes of Action of Coumarins and Some Comments on their Significance. New York: John Wiley \& Sons. 1997.

[3] Keating G. J.; O’Kennedy R. In Coumarins: Biology, Applications, and Mode of Action; The Chemistry and Occurrence of Coumarins. Eds. O’Kennedy R.; Thornes R. D. New York: John Wiley \& Sons. 1997.

[4] Weinmann I. Coumarins: Biology, Applications, and Mode of Action; History of the Development and Applications of Coumarin and Coumarin-related Compounds. Eds. O’Kennedy R.; Thornes R. D. New York: John Wiley \& Sons. 1997.

[5] Nielson B. E. Linnean Society of London. The Biology and Chemistry of the Umbelliferae.; Heywood V. H. Published for the Linnean Society of London, by Academic Press: New York. 1971.

[6] Murray R. D. H.; Méndez J.; Brown S. A. The Natural Coumarins, Occurrence, Chemistry and Biochemistry. John Wiley \& Sons: New York. 1982.

[7] Yamazaki H.; Tanaka M.; Shimada T. Highly sensitive high-performance liquid chromatographic assay for coumarin 7-hydroxylation and 7-ethoxycoumarin O-deethylation by human liver cytochrome P450 enzymes. J. chromatogr. B Biomed. 1999, 721, 13-19.

[8] Izquierdo M. E. F.; Granados J. Q.; Mir V. M.; Martinez M. C. L. Comparison of methods for determining coumarins in distilled beverages. Food Chem. 2000, 70, 251-258. 
[9] Ayaz N.; Bezgin F.; Demirelli K. Polymers Based on Methacrylate Bearing Coumarin Side Group: Synthesis via Free Radical Polymerization, Monomer Reactivity Ratios, Dielectric Behavior, and Thermal Stabilities. Isrn Polymer Sci. 2012, 2012, 1-13.

[10] Chen Y.; Hong R.T. Synthesis of Polyesters Containing Coumarin Dimer Components by Photopolymerization of 7,7'-Coumarinyl Polymethylene Dicarboxylates. J. Polym. Res. 1994, 1, 285-293.

[11] Trenor S. R.; Shultz A. R.; Love B. J.; Long T. E. Coumarins in Polymers: From Light Harvesting to Photo-Cross-Linkable Tissue Scaffolds. Chem. Rev. 2004, 104, 3059-3078.

[12] Allonas X.; Fouassier J.P.; Kaji M.; Miyasaka M. On the Ability of Coumarin Derivatives to Interact with Photoinitiators. J. Photopolym. Sci. Tec. 2000, 13, 237-241.

[13] Specht D. P.; Matric P. A.; Farid S. Ketocoumarins: A new class of triplet sensitizers. Tetrahedron. 1982, 38, 1203-1211.

[14] Specht D.P.; G.C. Houle; Farid S. U.S. Patent 4289 844,1981; Chem. Abstr. 1981, 94, 46756.

[15] Gualandi A.; Rodeghiero G.; Della Rocca E.; Bertoni F.; Marchini M.; Perciaccante R.; Jansen T. P.; Ceroni P.; Cozzi P. G. Application of coumarin dyes for organic photoredox catalysis. Chem. Commun. 2018, 54, 10044-10047.

[16] Monroe B. M.; Weed G. C. Photoinitiators for free-radical-initiated photoimaging systems. Chem. Rev. 1993, 93, 435-448.

[17] Abdallah M.; Dumur F.; Hijazi A.; Rodeghiero G.; Gualandi A.; Cozzi P.G.; Lalevée J. Ketocoumarin Scaffold for Photoinitiators for 3D Printing and Photocomposites. J. Polym. Sci. 2020, $58,1115-1129$. 
[18] Williams J. L. R.; Specht D. P.; Farid S. Ketocoumarins as photosensitizers and photoinitiators. Polym. Eng. Sci. 1983, 23, 1022-1024.

[19] Salmi H.; Tar H.; Ibrahim A.; Ley C.; Allonas X. Ketocoumarin/triazine/thiol as new high speed photoinitiating system for free radical polymerization under visible light in aerated media. Eur. Polym. 2013, 49, 2275-2279.

[20] Lalevée J.; Zadoina L.; Allonas X.; Fouassier J.P. New sulfur-centered radicals as photopolymerization initiating species. J. Polym. Sci. Part A: Pol. Chem. 2007, 45, 2494-2502.

[21] Fouassier J.P.; Lalevée J. Photoinitiators for Polymer Synthesis, Scope, Reactivity, and Efficiency; Wiley-VCH Verlag GmbH \& Co.KGaA: Weinheim, 2012.

[22] Fouassier J.P. Photoinitiation, photopolymerization, and photocuring: fundamentals and applications. Ed. Hanser, Munich; New York; Cincinnati. 1995.

[23] Fouassier J.P. Photochemistry and UV Curing. Ed. Research Signpost: Trivandrum, India. 2006.

[24] Dietliker K. A Compilation of Photoinitiators: Commercially Available for UV Today. SITA Technology Ltd.: Edinbergh, London. 2002.

[25] Zhou R.; Malval J.P.; Jin M.; Spangenberg A.; Pan H.; Wan D.; Morlet-Savary F.; Knopf S. A two-photon active chevron-shaped type I photoinitiator designed for 3D stereolithography. Chem.Commun. 2019, 55, 6233-6236.

[26] Li Z.; Zou X.; Zhu G.; Liu X.; Liu R. Coumarin-Based Oxime Esters: Photobleachable and Versatile Unimolecular Initiators for Acrylate and Thiol-Based Click Photopolymerization under 
Visible Light-Emitting Diode Light Irradiation. ACS Appl. Mater. Interfaces. 2018, 10, 1611316123.

[27] Qiu W.; Hu P.; Zhu J.; Liu R.; Li Z.; Hu Z.; Chen Q.; Dietliker K.; Liska R. Cleavable Unimolecular Photoinitiators Based on Oxime-Ester Chemistry for Two-Photon ThreeDimensional Printing. ChemPhotoChem. 2019, 3, 1090-1094.

[28] Abdallah M.; Hijazi A.; Graff B.; Fouassier J.-P.; Rodeghiero G.; Gualandi A.; Dumur F.; Cozzi P. G.; Lalevée J. Coumarin Derivatives as Versatile Photoinitiators for 3D Printing, Polymerization in Water and Photocomposite Synthesis. Polym. Chem. 2019, 10, 872-884.

[29] Garra P.; Dietlin C.; Morlet-Savary F. ; Dumur F.; Gigmes D.; Fouassier J.P.; Lalevée J. Photopolymerization processes of thick films and in shadow areas: a review for the access to composites. Polym. Chem. 2017, 8, 7088-7101.

[30] Mironov V.; Boland T.; Trusk T.; Forgacs G.; Markwald R.R. Organ Printing: computeraided jet-based 3D tissue engineering. Trends Biotechnol. 2003, 21, 157-161.

[31] Liu Z.; Zhang M.; Bhandari B.; Wang Y. 3D printing: Printing precision and application in food sector, Trends Food Sci. Tech. 2017, 69, 83-94.

[32] Ballard D. H.; Trace A. P.; Ali S.; Hodgdon T.; Zygmont M. E.; DeBenedectis C. M.; Smith S. E.; Richardson M. L.; Patel M. J.; Decker S. J.; Lenchik L. Clinical Applications of 3D Printing: Primer for Radiologists. Acad. Radiol. 2018, 25, 52-65.

[33] Balasubramanian K.; Sultan M.T.H.; Rajeswari N. Sustainable Composites for Aerospace Applications, Manufacturing techniques of composites for aerospace applications. Woodhead Publishing Series in Compos. Sci. Eng. 2018, 55-67. 
[34] Yadav S.; Gangwar S.; Singh S. Micro/Nano Reinforced Filled Metal Alloy Composites: A Review Over Current Development in Aerospace and Automobile Applications. Mater. Today Proceedings. Part E. 2017, 4, 5571-5582.

[35] Grande D. H.; Greist S.; Jessie T.; Daniel J. Reference Module in Materials Science and Materials Engineering, Comprehensive Composite Materials II, Composites in Sports Applications. Elsevier. 2018, 3, 469-526.

[36] W. C. Meuly. "Kirk-Othmer Encyclopedia of Chemical Technology” $3^{\text {rd }}$ ed., John Wiley \& Sons, New York. 1979.

[37] Horning E. C. “Organic Syntheses, Coll. Vol. III” John Wiley \& Sons, New York. 1955, 281.

[38] Hoefnagel A. J.; Gunnewegh E. A.; Downing R. S.; Bekkum H.v. Synthesis of 7hydroxycoumarins catalysed by solid acid catalysts. J. Chem. Soc., Chem. Commun. 1995, 225226.

[39] Ramani A.; Chanda B.M.; Velu S.; Sivasanker S. One-pot synthesis of coumarins. Catalysis by the solid base, calcined Mg-Al hydrotalcite. Green Chem. 1999, 163-165.

[40] Johnson J.R. Perkin Reaction and Related Reactions in Organic Reactions. 1942, 1, 210-265.

[41] Salem M. A.; Helal M. H.; Gouda M. A.; Ammar Y. A.; El-Gaby M. S. A.; Abbas S. Y. An overview on synthetic strategies to coumarins. Synth. Commun. 2018, 48, 1534-1550.

[42] Matos M. J.; Varela C.; Vilar S.; Hripcsak G.; Borges F.; Santana L.; Uriarte E.; Fais A.; Di Petrillo A.; Pintus F.; Era B. Design and discovery of tyrosinase inhibitors based on a coumarin scaffold. RSC Adv. 2015, 5, 94227-94235. 
[43] Dietlin C.; Schweizer S.; Xiao P.; Zhang J.; Morlet-Savary F.; Graff B.; Fouassier J.P.; Lalevée J. Photopolymerization upon LEDs: new photoinitiating systems and strategies. Polym. Chem. 2015, 6, 3895-3912.

[44] Lalevée J.; Blanchard N.; Tehfe M. A.; Morlet-Savary F.; Fouassier J.P. Green Bulb Light Source Induced Epoxy Cationic Polymerization under Air Using Tris(2,2'bipyridine)ruthenium(II) and Silyl Radicals. Macromolecules 2010, 43, 10191-10195.

[45] Lalevée J.; Blanchard N.; Tehfe M. A.; Peter M.; Morlet-Savary F.; Gigmes D.; Fouassier J.P. Efficient dual radical/cationic photoinitiator under visible light: a new concept. Polym. Chem. 2011, 2, 1986-1991.

[46] Rehm D.; Weller A. A. Kinetics of Fluorescence Quenching by Electron and H-Atom Transfer. Isr. J. Chem. 1970, 8, 259-271.

[47] Abdallah, M.; Le, H.; Hijazi, A.; Schmitt, M.; Graff, B.; Dumur, F.; Bui, T.-T.; Goubard, F.; Fouassier, J.-P.; Lalevée, J. Acridone Derivatives as High Performance Visible Light Photoinitiators for Cationic and Radical Photosensitive Resins for 3D Printing Technology and for Low Migration Photopolymer Property. Polymer. 2018, 159, 47-58.

[48] Zivic N.; Bouzrati-Zerelli M.; Kermagoret A.; Dumur F.; Fouassier J.P.; Gigmes D.; Lalevée J. Photocatalysts in Polymerization Reactions. ChemCatChem 2016, 8, 1617-1631.

[49] Lalevée J.; Fouassier J.P. Dyes and Chromophores in Polymer Science, Wiley-ISTE, London, 2016.

[50] Garra P.; Graff B.; Morlet-Savary F.; Dietlin C.; Becht J.M.; Fouassier J.P.; Lalevée J. Charge Transfer Complexes as Pan-Scaled Photoinitiating Systems: From $50 \mu \mathrm{m}$ 3D Printed Polymers at $405 \mathrm{~nm}$ to Extremely Deep Photopolymerization (31 cm). Macromolecules 2018, 51, 57-70. 
TOC graphic:

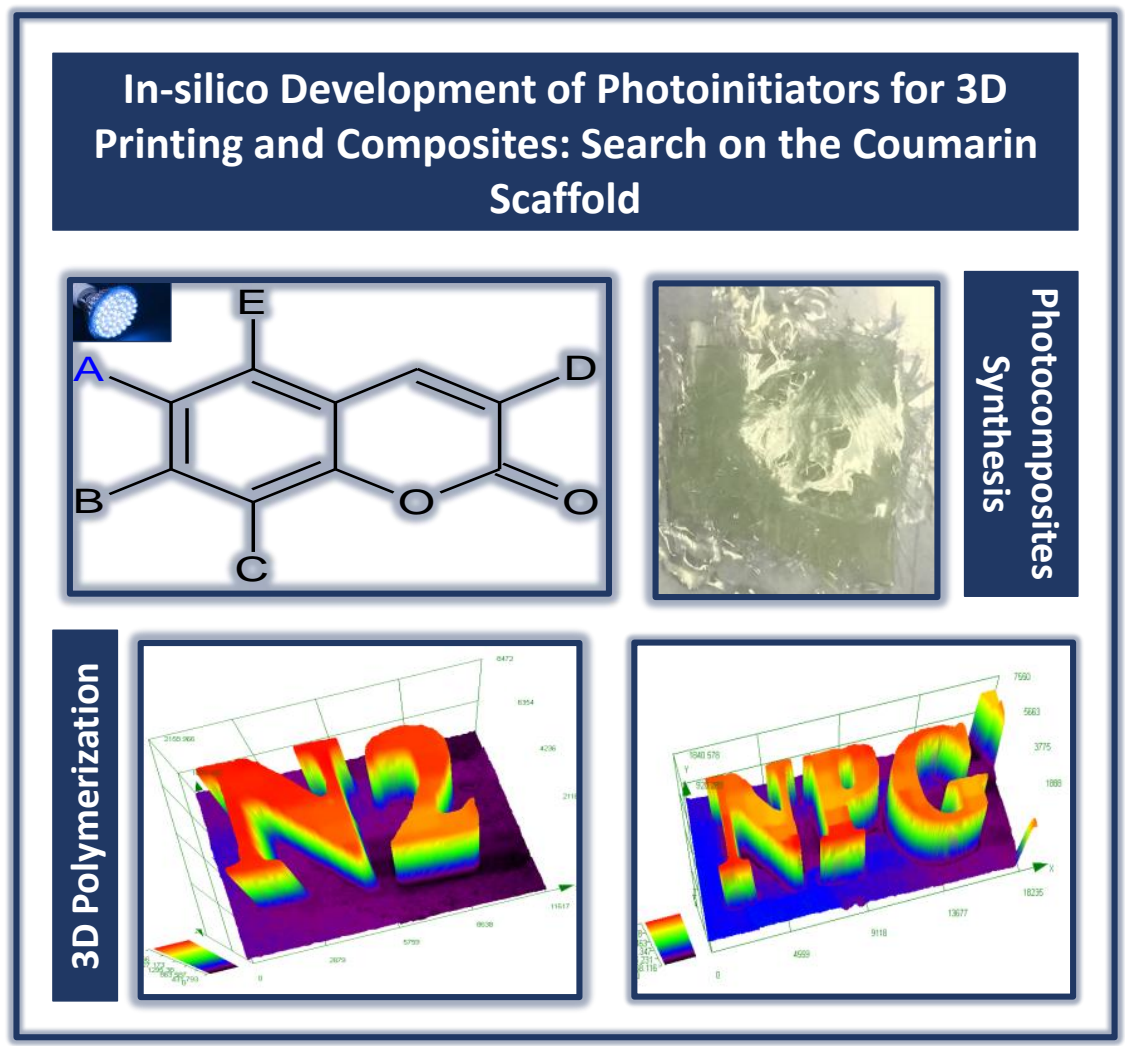

